\title{
Effect of outsourcing strategies on the performance of small and medium scale enterprises (SMEs)
}

John I. Agburu', Nyianshima Calvin Anza ${ }^{2 *}$ and Akuraun Shadrach lyortsuun ${ }^{2}$

\author{
* Correspondence: \\ anzagbem@gmail.com \\ ${ }^{2}$ Department of Business \\ Administration, Federal University, \\ Taraba State, Wukari, Nigeria \\ Full list of author information is \\ available at the end of the article
}

\begin{abstract}
Several organizations have embarked on outsourcing strategies over the years but many still suffer in terms of their goal achievement; some have experienced low productivity both in terms of quality and quantity, their profitability has not been stable, and their capacities are grossly underutilized. This research work determined the effect of outsourcing strategies (back office activities, primary activities, accounting activities and supporting activities) on the performance of Small and Medium Scale Enterprises (SMEs). Survey research design was adopted in Benue State, Nigeria. Stratified random sampling technique was used in selecting respondents for a primary source data gotten through a well-designed and self-administered questionnaire. Also, secondary data was sourced from the financial records of ten (10) selected SMEs. The variables were statistically analyzed using multiple regression technique. At the end of the research, the study found that; outsourcing of back office activities (such as bookkeeping, payroll, billing, order processing, payment processing, cleaning services, security services and other administrative activities); outsourcing of primary activities (such as manufacturing, purchases, warehousing, Sales force and customer service); outsourcing of Supporting activities(such as shipping, IT services/system, training, advertising, legal services, transport services, public relations) has a significant effect on organizational profitability of SMEs whereas, outsourcing of accounting activities(such as financial reporting, tax processing) has no significant effect on performance of SMEs. This study therefore recommended that SMEs should embark more on outsourcing strategies to attain the benefits of cost savings/restructuring which results in better customer service at profit; also, outsourcing process management through follow up steps like effective communication and monitoring should be employed and taken seriously to better reap the benefits of this maintenance/growth strategy. Also, SMEs should ensure that, the costs of managing the outsourcing process is not greater than the benefits generated by the outsourcing program.
\end{abstract}

Keywords: Outsourcing strategies, Performance and small and medium scale enterprises

\section{Background}

Business environment in today's world is severely dynamic (Jae, Minh, Kwok and Shih, 2000). Rapidly changing and increasingly complex business issues are creating key shift in organizations and the manner in which they do business (Sev, 2009). One fact is still certain; every organization has its goals; also, the success of an organization is measured by the level at which it attains its goals.

(c) The Author(s). 2017 Open Access This article is distributed under the terms of the Creative Commons Attribution 4.0 International License (http://creativecommons.org/licenses/by/4.0/), which permits unrestricted use, distribution, and reproduction in any medium, provided you give appropriate credit to the original author(s) and the source, provide a link to the Creative Commons license, and indicate if changes were made. 
In order to achieve its set goals in the presence of technological advancement, sophistication of business processes, knowledge explosion and need for constant growth, an organization looks out for strategies to enhance performance (Dominguez, 2006). It therefore reflects on the capabilities of its workers (staff), its technological knowhow, business processes and so on, and answers the question of whether it can achieve its goals with what it already has on ground or look out for ways to complement ( $\mathrm{Sev}$, 2009; Isaksson and Lantz, 2015). In struggling to meet the demands of customers and shareholders, an organization may look out for ways that it has a comparative advantage. It therefore focuses on core competences and seeks to reduce operation cost which presents outsourcing as the right strategy (Akewushola and Elegbede, 2013).

Outsourcing is one management tool that has gained relevance among managers in addressing today's business dynamics (Jae, et al. 2000). It entails contracting out of a business function (Jae, et al. 2000; Dominguez, 2006; Isaksson and Lantz, 2015). It is the replacing of in-house provided activities by subcontracting it out to external agents. Consequently, the management and development of innovations in outsourced activities become the responsibility of an agent external to the firm.

Outsourcing avails organizations the opportunity to concentrate her core competencies on definable preeminence business area and provides a unique value for customers Dominguez (2006; Gro"ßler, Laugen, Laugen and Fleury, 2012). Also worthy of note is the fact that present day outsourcing is no more limited to peripheral activities such as cleaning, catering and security. As noted by Jennings (1997) and Dominguez (2006), outsourcing also includes critical areas such as design, manufacturing, marketing, distribution, information system etc.

Outside Nigeria, notable companies which have outsourced are among others Kodak Company who subcontracted its computing operations to International Business Machines (IBM); the result of which was higher quality computing system and operation at Kodak for less money than it was spending (Sev 2009). Also as noted by Hill (1997), Boeing as at 1997, was world's largest manufacturer of commercial jet aircraft with a $60 \%$ share of the global market. Despite the large share of the market, Boeing was faced with competitors like Europe's Airbus industries. The dog fight between the big two resulted to high operating cost which made Boeing to look out for ways to beat down cost. In 1993 Boeing undertook a companywide review of its make or buy decision. In pursuit of this decision, Boeing decided and outsourced certain components to China. Worthy of note is the fact that Boeing avoided outsourcing the production of wings because it believed that doing so might give away valuable technology to potential competitors.

In Nigeria, Sev (2009) noted some examples of companies who have outsourced their operations. The examples are Ashaka Cement Plc, which outsourced its operations and services to Blue Circle industries of United Kingdom; Dangote Cement, Gboko (Benue) plant which acquired the expertise of Pakistani who have managerial know-how and expertise to give quality services and operations. Notable also is in the banking sector. Several Nigerian Mega banking groups have outsourced their operations and services to "Experts" to enhance global competition in the international financial markets. The United Bank for Africa (UBA) plc, Access Bank plc, and other universal banks in Nigeria outsourced Automated Teller Machines (ATM) to a company called interswitch. Similarly, most banks' recruitment exercises are being outsourced to other human resource companies like Dragnet and Philips consulting. 
All the organizations identified so far are by all standards, big organizations. It is therefore pertinent to submit here that, all forms of organizations engage in one form of outsourcing or another regardless of their size (whether small or large) (Isaksson \& Lantz, 2015). Be it manufacturing, services, information technology, management services, product engineering, and research process or marketing services (Suraju \& Hamed, 2013). It is usual sight to see SMEs collect contracts from their customers and rather than do it themselves turn out to subcontract them to other organizations, either small or big to execute them for them. Instances of such outsourcing in Nigeria can be seen in the outsourcing of security services from security outfits by some hotels that focus on rendering hotelier services which is their core operation.

Also, a pilot study conducted revealed that, most SMEs outsource their major accounting operations to external accounting firms instead of employing accountants. They most at times have one or few accountants whose job is to record transactions and then acquire the services of external accountants who do the computation and preparation of sophisticated accounts and also audit their operations. Other areas of outsourcing by SMEs as noted by Isaksson and Lantz, (2015) and Akewushola and Elegbede, (2013) are training of staff, advertising and other supporting activities.

The reasons for outsourcing over the years are seen as to pave way for an organization's concentration on their core competencies thereby experiencing effectiveness and efficiency through cost savings, reduced capital investment within the firm, improved responsiveness to changes in the business environment, increased competition among suppliers ensuring higher quality goods and services in the future, reduced risk of changing technology, among others (Jae, et al. 2000; Dominguez, 2006; Sev, 2009; Isaksson and Lantz, 2015).

In line with the above established merits of outsourcing, several organizations (some of which are noted above) have ventured into outsourcing. However, as noted by Sev (2009), despite the outsourcing they have been carrying out over the years, some organizations still suffer in terms of their goal achievement; some have experienced low productivity both in terms of quality and quantity, their profitability has not been stable, and their capacities are grossly underutilized.

Based on research findings over the years also, researchers have theorized reasons and areas of outsourcing and its strategies. For instance, C.K. Prahalad and Gary Hamel advocated the theory of core competencies which insists on outsourcing of non-core areas as a best practice in utilizing of resources (Prahalad and Hamel, 1990; Jae, et al. 2000; Dominguez, 2006); yet, organizations are seen outsourcing even their primary operations which is seen as their area of competence. Also, some look at the cost of operation thereby outsourcing to minimize cost (Busi and McIvor, 2008), yet some organizations give out some operations that they can carry out in a cheaper way. The question here is that; are they looking at quality or their decisions are based on social reasons as noted by the social view theory (Jae, et al. 2000) or what?

The case of SMEs has been so peculiar here. Their outsourcing is in addition to the backup/supporting activities, more of their core areas which are before now being retained in-house (Isaksson and Lantz, 2015). This research therefore delved in the specific outsourcing strategies embarked upon by these SMEs; why their choice and the effect of various strategies on organizational performance of these SMEs.

This research work explored outsourcing activities among SMEs in Gboko, Makurdi and Otukpo metropolis of Benue State, Nigeria with emphasis on organizational operations for 
the recent past five years (2012 to 2016). Small and Medium Scale enterprises here are defined in line with the definition of SMEs by the National Council of Industries in Onugu (2005) as any enterprise whose total worth including working capital but excluding value of land is more than ten (10) million naira but less than one hundred million naira (N300, 000,000.00); a workforce between eleven (11) and seventy (200) full-time staff and/ or with a turnover of not more than twenty million naira $(\mathrm{N} 20,000,000)$ in a year. The main research objective was to determine the exact effect of outsourcing strategies on the performance of SMEs, hence, the following questions are asked;

i. How has the outsourcing of Back Office Activities affected the profitability of SMEs?

ii. What are the effects of Outsourcing Primary Activities on the profitability of SMEs?

iii. What are the effects of Outsourcing Accounting Activities on the profitability of SMEs?

iv. What is the contribution of Outsourcing Support Services to the profitability of SMEs?

\section{Conceptual framework}

Just like any other concept in the academic world, outsourcing has diverse definitions. This is due to the diverse nature of the perceptions of those who use it. It is therefore not feasible for one to state in a clear cut manner a definition that is generally acceptable. However, for the purpose of this research, the definitions by Yalokwu (2006) and Dominguez (2006) are relevant and so adopted. Outsourcing is defined according to Yalokwu (2006:590), as the process of subcontracting operations and services to other firms that specialize in such operations and services that can do them cheaper or better (or both). Also, Dominguez (2006:1) views outsourcing as the practice of hiring functional experts to handle business units that are outside of a firm's core business. She describes it as a method of staff augmentation without adding to headcount.

Base on the above definitions, outsourcing can be comprehensively said to be the contracting and/or subcontracting of operations and services whether they are outside of a firm's core business or not to other firm(s) that specializes in it and can do it better or cheaper (or both). This definition supports the fact that organizations have their areas of specializations. An organization that performs its administrative and business services and operations may not perform all of them efficiently. This may lead to low quality products/services. When an organization focuses on areas that it has advantage comparatively and outsource those it performs minimally this would lead to efficiency and high quality productivity. The emphasis of this research however, is on the outsourcing strategies of SMEs, their implementation and contributions to organizational performance.

\section{Outsourcing strategies}

Outsourcing strategies have been classified by different scholars in different ways. Some of the classifications are here reviewed and a choice made at the end.

\section{i. Classification according to Jennings (1997)}

According to Jennings (1997) as reported by Sev (2009), outsourcing strategies can be categorized into the principal type and the common type. The principal type entails traditional outsourcing: Here the routine jobs or task that the staff of the organization 
does not perform are identified and the service providers aired for the job and Greenfield outsourcing: Without hiring the service provider the organization can directly hire an imminent company which can execute their business which was not done in the organization internally (Sev, 2009). The common type on the other hand includes: Information technology (IT) outsourcing, Call centre, Payroll, Finance functions and activities, E- publishing, Book-keeping service, Accounting, Human resources and Computer Aided Design (CAD) service (Sev, 2009).

This classification however, is not quite explicit to be used in defining the outsourcing strategies of SMEs. Also, most outsourcing is perceived as human resource management strategy, as such listing human resource outsourcing as a strategy amongst others which obviously entails the use of human resource without adding to head count is rather confusing.

\section{ii. Classification according to Harward (2010)}

According to Harward (2010), there are four (4) outsourcing strategies at an organization's disposal. These four types of outsourcing strategies or what some call engagement models for sourcing are largely grouped into two. The first two are considered business process outsourcing (BPO) engagements, and the other two are considered out-tasking models. The BPO models are comprehensive and selective. And the outtasking models are licensing and contracting. The four sourcing strategy model is shown diagrammatically in Fig. 1;

A common question is "what is the difference between BPO and out-tasking?" The easiest way to explain it is to look at an organization as an integrated group of business processes that must be managed by someone (Harward 2010). In small businesses, the business processes can be grouped into four functional areas of; administration, content, delivery, and technology. The number of processes a supplier manages, the complexity integrating those processes, and the duration of time a supplier is expected to manage those processes all help define the differences in outsourcing strategies.

$\mathrm{BPO}$ refers to those engagements that are most complex, longer in duration, integrated across functional process areas, and considered most strategic to the business

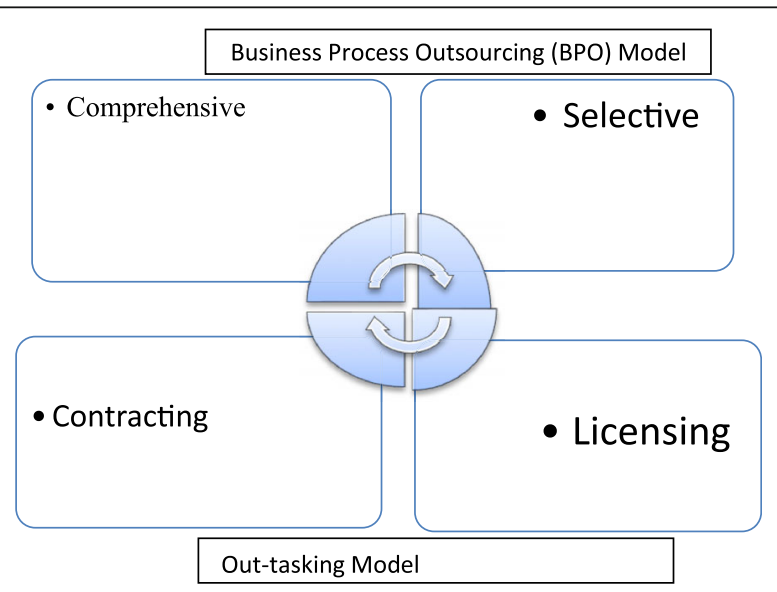

Fig. 1 Classification of Outsourcing Strategy according to Harward (2010). Source: Harward, (2010) 
whereas, out-tasking refers to the models that are less complex, fewer processes and limited to one functional area, more tactical, and more labor oriented (Harward 2010). These four types of outsourcing strategies are briefly differentiated below:

1. Comprehensive BPO - this is the most complex, strategic, long term, and demanding relationship you can have with a supplier. A comprehensive outsourcing deal means that you are engaging with a partner for a multi-year period to strategically manage a comprehensive set of processes across all four functional process areas of your organization (Harward 2010). Both parties are willing to commit dedicated resources to the deal which means you are both committing people and finance over an extended period of time. Comprehensive does not imply that the supplier does everything associated with task for your company. Even in a comprehensive engagement, you as the buyer still must manage some processes like client relationship management or strategic planning. The idea that you give away all responsibility to the supplier is actually a myth, and never happens in real life.

2. Selective BPO - this is also a very complex engagement, but somewhat less than a comprehensive deal because of the reduced integration of functional processes. In selective outsourcing, you engage a partner to manage multiple processes within one functional area (administration, content, delivery, or technology) but not process across functional areas (Harward 2010). Here you may contract with a supplier for the next three years to manage all custom content development activities for product elearning courses. But the supplier would not deliver any courses, manage registration or admin services related to the transaction, nor host or support the courses online. Contracts for selective BPO deals are similar to those of comprehensive BPO but they are somewhat less complicated because there are fewer processes involved.

3. Licensing Agreement - these engagements are forms of out-tasking and used when sourcing a tangible asset, such as a technology or real estate. Licensing agreements for technology usually take the form of software as a service (SaaS) contracts (Harward 2010). When the cost of implementation and set-up are high, these deals are often times multi-year. This allows the client to amortize costs over longer periods of time. When these costs are low, deals often take the shape of month to month. Contracts for license agreements are generally purchase orders with defined terms and a unit price in the form of price per time.

4. Contracting - the second form of out-tasking engagements and the most common form of outsourcing in the small business industry is contracting. Some refer to it as a 'labor for hire' engagement (Harward 2010). It's where we pay a contractor by the hour/day/week/month to perform a task. Contracting is commonly used when we source a supplier to manage a project, and we compensate them when the project is completed. The project can be consulting, instructional design, delivery of a course, etc. It is a tactical engagement when your objective is to limit the complexity and breadth of processes you expect the supplier to manage. It is transactional, which means the relationship ends when the activity is complete. It is the most flexible, least risky and easiest to manage relationship for the buyer. It limits your obligations to a supplier and allows you to easily terminate a contract when things are not going well. Contracts are generally purchase orders with 
defined terms of activities for a unit price for each deliverable. Unit prices are usually in price per time or price per project terms.

This classification according to Harward (2010) is also seen as not being explicit enough. The two groups of strategies (Business Process outsourcing strategies and out tasking strategies) are so inter related such that the last two (contracting and licensing) are seen as been sub of the first two (Comprehensive and selective). Also, while the first two measure the extent of outsourcing, the last two measure but the area of outsourcing.

\section{iii. Classification according to Gilley and Rasheed (2000)}

According to Gilley and Rasheed (2000), outsourcing strategies can be grouped into four strategies housing related activities commonly outsourced. These four strategies are:

1. Outsourcing of back office activities

2. Outsourcing of primary activities

3. Outsourcing of accounting activities

4. Outsourcing of support activities

Isaksson and Lantz (2015) based on the classification by Gilley and Rasheed (2000) fit in sixteen (16) sub activities commonly outsourced in the strategies base on their characteristics. An improved version of these activities is here presented for this research. The classification is shown in Fig. 2.

The four strategies are further discussed below:

\section{Back office activities}

Back office activities are the non core activities that an organization needs to pave way for the day to day running of their office/business. As the name suggests, back-office refers to the functions which are required to be carried out efficiently to ensure the success of the business, but these services do not fall into the core operations functioning

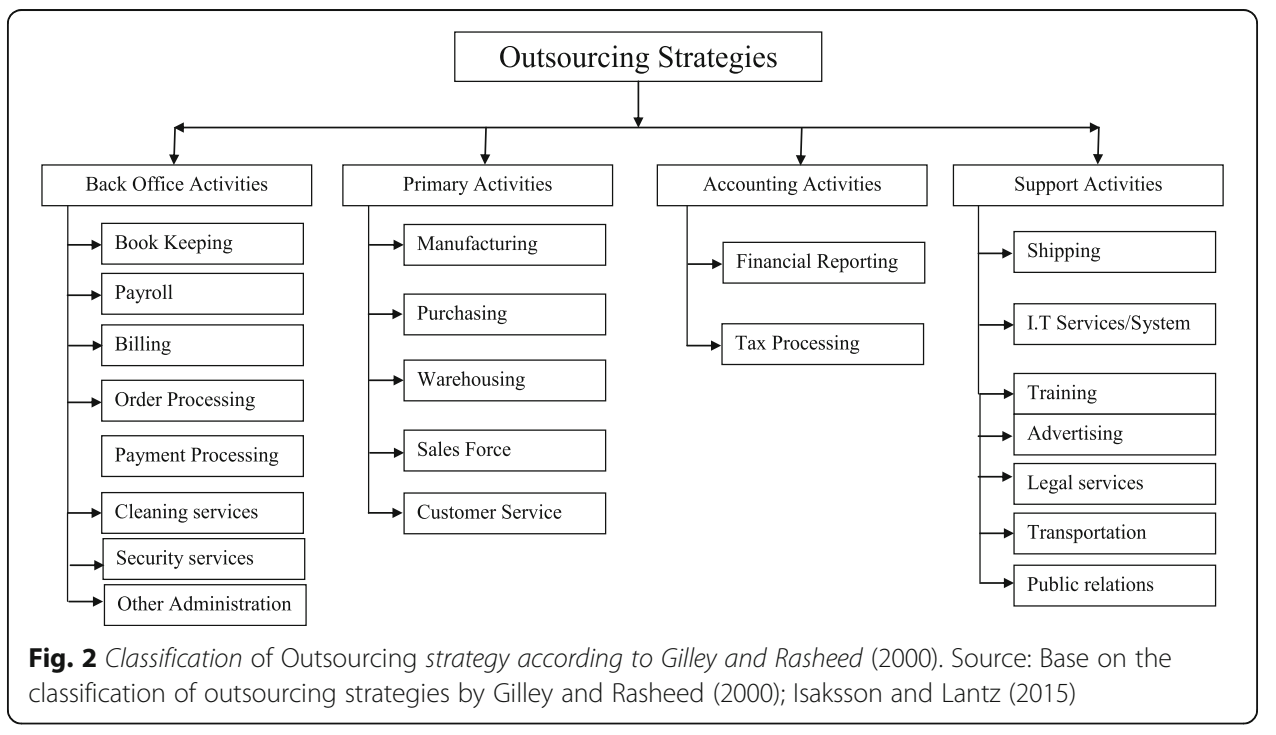


of the firm (Isaksson and Lantz, 2015). Back-office operations are considered to be the backbone of an enterprise and hence are no less important than the essential functions. Apparently, back-office outsourcing has been on the rise in recent years as they are quite crucial to the core activities of any enterprise. There are many benefits of outsourcing back office functions. Some are; focus on core operations, Job carried out by professionals with domain expertise, higher level of flexibility, access to state of the art technology and infrastructure, Lowered costs and no hassle of staff acquisition and retention (Sev, 2009).

In outsourcing, one is advised to ensure that, they don't have the resources to do it, they don't have the know-how to do it well, they don't have the experience with the process at all and trying to manage the process internally will actually hurt the organization (TaskUs, 2014).

Some of these activities as noted by Gilley and Rasheed (2000) are bookkeeping, payroll, billing, order processing, and payment processing. Others are cleaning services, security services and other administrative activities which are needed by organizations to better serve their customers (Dominguez, 2006). These back office activities when outsourced rightly improves an organizations performance (Steensma and Corley, 2000). It is a means of reducing costs, increasing quality, and enhancing a firm's overall competitive position (Frayer, Scannell and Thomas 2000). This improves one's competitive edge.

\section{Primary activities}

The primary activities outsourcing practice stems more from the resource availability and cost advantage. The resource-based view of the firm and transaction cost economics provides a comprehensive explanation of the conditions which lead firms to resort to the outsourcing of primary activities and of the reasons why such outsourcing has grown in importance in recent years (Isaksson and Lantz, 2015).

Many organisations today outsource even their primary activities. For instance, the footwear manufacturer Nike has long been renowned for the fact that it does not own any manufacturing facilities, but subcontracts out the manufacture of its products to independent suppliers.

It is argued that certain firms choose to outsource primary activities within their production chains to independent suppliers, not because of relative capability considerations, but because they are able to leverage their resources to appropriate the rents from the chain whilst reducing their asset base. The activities which are directly related to the primary operations are manufacturing, purchases, warehousing, Sales force and customer service (Isaksson and Lantz 2015).

\section{Accounting activities}

More recently, some businesses have begun outsourcing at a more strategic level not just to reduce costs in non-core processes but to improve business performance. This is being driven by a number of factors such as competitive and budgetary pressures, advances in technology and communications and the need to transform the finance and accounting function (Krell, 2007).

Finance and accounting outsourcing (FAO) has undergone major transformation over the years (Hayward, 2002). The market for FAO has matured in terms of the type of work undertaken from routine, transactional work to delivering customized, complex and higher-value services (such as fore casting and planning and treasury) (Hayward, 2002). 
Some companies are consolidating their outsourcing work, citing reduction in complexity, streamlining operations and increased efficiency as benefits, while others are still taking a multi-sourcing route based on particular provider expertise (Hayward, 2002).

Also, globalization of services opens up new opportunities for companies to outsource finance activities to service providers worldwide (Hayward, 2002). Companies which choose to outsource one or more finance processes continue to benefit from global differences in wages, and they access new talent and expertise (such as in systems implementation and process improvement) to create further competitive advantages.

According to Kumaran (2013), Organizations, these days, not only look for costeffective solutions to systematically run non-core activities like accounting and payroll services, but also expect to add value in order to achieve better control and understanding of cash flow and thereby make informed decisions. In spite of being considered as non-core, accounting services form an integral part of an organization's operational capabilities and systematic functioning. Therefore, outsourced accounting and payroll services definitely help streamline core business operations of an organization (Kumaran, 2013). Kumaran (2013) further highlighted top 10 advantages of outsourcing accounting and payroll services as; achieving high level of accuracy, cost effective services, fraud check, direct deposit through efficient payroll processing, avoiding penalties during tax processing, reaping benefits with up-to-date technology, saving up on processing time, gaining from the assistance of experts, avoiding reconciliation worries related to financial institutions and staying informed with up-to-date accounting status.

The above notwithstanding, Isaksson and Lantz (2015) asserts that, the activities which are typically performed by outside accountants that can be grouped under accounting activities include those of financial reporting and tax processing. Their classification forms a basis for this research.

\section{Support activities}

Just like in the case of back-office activities, support activities help in the efficient running of a business (Isaksson and Lantz, 2015). These activities support the core activities in an organization (Sev, 2009). Support services as noted by Isaksson and Lantz (2015) include activities such as; shipping, IT services/system, training, advertising, legal services, transport services, public relations.

This classification of outsourcing activities by Gilley and Rasheed (2000) is therefore adopted for this research. The choice of this classification is due to its explicit nature. It points out clearly, the activities which are being outsourced and also, succinctly classified base on its peculiarities. A pilot survey also shows clearly the fact that, these activities are usually outsourced by SMEs at various extents.

\section{Outsourcing and organizational performance}

Organizational performance is measured in different ways depending on the intent. However, whatever criteria is used, organizational Performance is the output of the organization. Kotabe et al. (1998) identifies three types of performance measures as necessary components in any outsourcing performance measurement system: strategic measures; financial measures; and quality measures. Other studies use additional dimensions of market performance such as costs savings, cycle time, customer satisfaction, and 
productivity to measure the effectiveness of outsourcing strategy (Malhorta, 1997; Carney, 1997; and Goldstein, 1999).

Organizational Performance here is seen as the output of the organization measured in terms of profitability. Profitability is measured in terms of Cost savings, Focus on core business (thus increasing efficiency), Reduction in money spent on fixed assets (cost restructuring), Reduction in tax paid (tax benefit) and Increase turnover (Sales).

In tracing the relevance of outsourcing to organizational performance also, many authors including Quinn, (1992); Gupta and Zheuder, (1994); Greer et al., (1999); Lever, (1997); Sharpe, (1997); Steensma and Corley, (2000); Yalokwu (2006) and Dominguez (2006) submitted that, outsourcing can improve organizational performance when applied as an organizational strategy.

Outsourcing one's business processes can improve one's competitive edge (Dominguez, 2006). The reason behind this is that outsourcing reduces business costs (Yalokwu, 2006; Dominguez, 2006; Kroes, J.R. and S. Ghosh, 2010). Organizations may choose to outsource with certain business aims in mind. The aim might be the need to improve on financial performance (Isaksson and Lantz, 2015). Most times, such organizations are aware that outsourcing firms may offer them an opportunity to work cheaply through efficient technology and economies of scale. By minimizing costs, organizations can achieve their economic related goals and this enhances their organizational performance (Leavy, 2004). Consequently, the extra amount that would have been passed to the consumers in the form of higher prices for the goods and services now becomes irrelevant as consumers pay less for their commodities (Dominguez, 2006). This allows businesses to compete favorably based on price thus giving them a competitive edge (Yalokwu, 2006).

Organizations that do everything on their own may be exposed to greater levels of risk than those who outsource their business functions (Dominguez, 2006). Most time, the former mentioned organizations may face difficulties trying to balance between choosing the right alternatives, training their employees in that area of interest, increasing reliability, and maximizing efficiency. By doing everything on its own, an organization may have a difficult time trying to eliminate risks, and usually run the risk of spending too much on infrastructural capital (Dominguez, 2006; Akinbola, Ogunnaike and Ojo, 2013). Consequently, this eats into their profitability and reduces their chances of growing their organization's businesses. However, through outsourcing, organizations can minimize their risks with regard to huge infrastructural expenditures and the overall result of this issue is that more investors will be attracted to such organizations (Yalokwu, 2006; Dominguez, 2006; Sev, 2006; Bustinza, Arias-Aranda and Gutierrez-Gutierrez, 2010).

Outsourcing is good for business because there are certain situations that can be avoided through it (Sev, 2006). For instance, organizations that perform all their business functions may have to spend huge amounts on replacing obsolete technology (Dominguez, 2006). However, when that business function is outsourced, then organizations will not even feel the pinch. Frayer, Scannell and Thomas (2000) suggest that companies are increasingly viewing outsourcing strategies as a means of reducing costs, increasing quality, and enhancing a firm's overall competitive position.

This means that organizations can dedicate their resources to productive activities alone and thus enhance their effectiveness and efficiency (Frayer et al. 2000). Successful implementation of an outsourcing strategy has been credited with helping to cut cost (Gupta and Zheuder, 1994; Greer et al., 1999), increase capacity, improve capacity, 
improve quality (Lau and Hurly, 1997; Kotabe et al., 1998), increase profitability and productivity, improve financial performance, lower innovation costs and risks (Quinn, 2000), and improve organizational competitiveness (Lever, 1997; Sharpe, 1997; Steensma and Corley, 2000). Nevertheless, outsourcing does generate some problems, as outsourcing usually reduces an organization's control over how certain services are delivered, which in turn may raise the organization's liability exposure (Dominguez, 2006).

\section{Achieving success or failure of outsourcing strategies}

Organizations consider their outsourcing projects successful when the benefits generated by the outsourcing strategies are greater than the costs of developing the required resources and capabilities through internal development or acquisitions (Isaksson and Lantz, 2015). Meanwhile, organizations consider their outsourcing projects unsuccessful or as a failures, when the costs of managing the links between outsourcing partners were greater than the benefits generated by the outsourcing program (Sev, 2006). This finding is consistent with previous studies on alliances success and failure (Foster, 1999).

Successful firms identified their clear objectives and expectations of outsourcing activities as the most useful and contributing factors to their outsourcing effort. Outsourcing must be done carefully, systematically, and with explicit goals and expectations. Sensible reasons to consider outsourcing include both strategic and tactical concerns on both a department and organizational level. A good choice of outsourcing partners was the most useful and contributing factor among successful organizations. Outsourcing partners should be selected based on their expertise in the operation being outsourced and their cultural fit with the organization. Another factor is providing adequate training skills needed to manage outsourcing activities and to negotiate a sound contract. Providing managers with skills that will enable them to adapt to other cultures and work with other managers may be very important to ensure the success of outsourcing. Developing a comprehensive plan outlining detailed expectations, requirements, and expected benefits during all phases of outsourcing activities may be the key to successful sourcing efforts (Guterl, 1996).

Effective communication among cross-functional areas reduces the negative effects of outsourcing projects on the morale and performance of the remaining employees. Management must step in and rebuild trust among the workers, and jobs may need to be evaluated and expanded or changed to fit the new organization. This can be achieved through support and involvement of top management and by providing incentives to employees and vendors who meet and exceed the contracted performance expectations (Jones, 1997; Foster, 1999). Another factor is to acquire the right people, with the right skills involved in all phases of outsourcing activities. Early in the evaluation, persons must be identified as to who will take leadership responsibility, perform the analysis, and make the decisions. Adequate supporting infrastructures, commitment by top management, and development of objective performance criteria were among the factors contributed to successful outsourcing projects. Properly defined performance criteria for an outsourcing engagement are objective, quantifiable, and collectible at a reasonable cost, and should be metrics, which can be benchmarked against performance of other organizations and providers (Ramarapu et al. 1997; Kleepes and Jones, 1999). Other factors identified among 
the top priorities in successful firms include adequate performance feedback, emphasis on both short and long-term benefits, anticipation of change for both good and bad times and accommodation of cycles of demand that require an adjustment in services.

Nevertheless, unsuccessful firms identified the fear of change, including fear of job loss as the most serious problem facing their outsourcing efforts. Dealing with these fears through communication and honesty is important to managing this factor (Jones, 1997; Quinn, 2000; Dominguez, 2006). A poor choice of outsourcing partners was the second most serious problem facing unsuccessful organizations. Establishing strategic supplier alliances and adoption of the philosophy that the firm is a partner with the suppler may help alleviate this problem (Lau and Hurly, 1997; Dominguez, 2006; Sev, 2006). The third factor was not providing enough training/skills needed to manage outsourcing activities. The individuals responsible for managing the outsourcing relationship should receive specific training that includes a complete understanding of the business goals of the contract, the specific performance criteria agreed upon, and individual roles. This training and communication can also help reduce resentment or resistance (Foster, 1999; Dominguez, 2006; Sev, 2006).

Inadequate comprehensive plans outlining detailed expectations, requirements, and expected benefits of outsourcing efforts was the fourth factor identified by unsuccessful firms in their outsourcing projects (Dominguez, 2006). Somewhat surprisingly, given the nature of outsourcing activities, the following obstacles were ranked lower than other problems in respondents outsourcing efforts: inadequate control systems over how certain services are delivered, which in turn may raise the company's liability exposures (Guterl, 1996), and hidden costs and risks such as travel costs, license transfer fees, exchange rates, and foreign taxes on products and services (Ramarapu et al. 1997). In addition, significant was that unsuccessful organizations did not generally consider lack of high-level management support to be a serious problem, which probably means there was support and involvement by top management in these organizations.

Organizations that outsource should continue to monitor the contractors' activities and establish constant communication (Guterl, 1996). Another big problem with outsourcing comes from the workers themselves, as they fear loss of jobs (Malhorta, 1997). According to a recent survey, 55\% of outsourcing relationships fail in the first five years. Of these that do manage to stay together, $12 \%$ are unhappy with their arrangement and regret ever making the deal (Foster, 1999). Other problems identified including poor organizational communication, cross functional political problems, unclear expectations, lack of flexibility, keeping contracts short, and taking a tactical rather than a strategic approach to outsourcing activities. Also, despite the significant growth of the outsourcing concept, most organizations embarking on these projects do not achieve their intended result. Quinn (2000) estimates that as many as 40 to $50 \%$ do not achieve the improved results they seek. This is attributed to poor implementation of outsourcing strategies rather than a problem with the concept itself (Quinn, 2000).

According to Ellram et al., outsourcing has implications for day-to-day management and performance, as well as strategic implications. Therefore, companies must outsource intelligently. Outsourcing decisions may affect company's cost structures, longterm competitive situation and can also alter the nature of risks that the company must manage. Hence, it is crucial for management to understand and have a clear conceptual 
framework of their outsourcing decision. Furthermore, it is also important that company must know the benefits and risks of outsourcing (Yalokwu, 2006; Sev, 2006). The increasing use of outsourcing arrangements, as well as the unfamiliar complexity associated with it especially in developing countries suggests the need to probe further about how to effectively utilize this strategy (Sev, 2006). Worthy of note is the fact that, even though there are evidences of outsourcing at the small and medium scale level, there is very little empirical works supporting it (Isaksson \& Lantz, 2015). That notwithstanding, outsourcing enhances service provision of SMES. It provides additional income for businesses even without spending (Isaksson \& Lantz, 2015).

\section{Theoretical framework}

It is difficult, if not impossible, to agree on the origin of outsourcing as a practice and/ or a scientific concept. Some researchers, mostly from the manufacturing and supply chain management background, would arguably see it as nothing more than an evolution of older researches on "make-or-buy" (Busi and McIvor, 2008). These theories are summarized in Table 1 below:

\section{Discussion and application of these theories:}

According to Prahalad and Hamel (1990) as supported by Jae, et al. (2006), there are two theories most often referred to in relation to outsourcing; these are the Core Competencies Theory (Resource-Based Theory) and Transaction Costs Theory. This research however will be based on these two generally used theories and a third which is presented in generic form- the social view theory. Thus, the theories to be discussed are:

Table 1 The key distinctions among major theories used in outsourcing research

\begin{tabular}{|c|c|c|c|c|}
\hline Orientation & Theory & Focus & Resource & Main constructs \\
\hline \multirow[t]{2}{*}{$\begin{array}{l}\text { Strategic } \\
\text { Management } \\
\text { View }\end{array}$} & $\begin{array}{l}\text { Resource } \\
\text { Based }\end{array}$ & $\begin{array}{l}\text { Internal slack } \\
\text { resource }\end{array}$ & $\begin{array}{l}\text { Physical capital, } \\
\text { Human capital, } \\
\text { Organizational } \\
\text { capital }\end{array}$ & $\begin{array}{l}\text { 1. Value, } \\
\text { 2. Rareness, } \\
\text { 3. Imperfect immutability, } \\
\text { 4. Non substitutability }\end{array}$ \\
\hline & $\begin{array}{l}\text { Resource } \\
\text { Dependence }\end{array}$ & $\begin{array}{l}\text { External } \\
\text { resource } \\
\text { (Uncertainty) }\end{array}$ & $\begin{array}{l}\text { Land, } \\
\text { Labor, } \\
\text { Capital, } \\
\text { Information, } \\
\text { Products (service) }\end{array}$ & $\begin{array}{l}\text { 1. Task dimensions (Concentration, } \\
\text { Munificence, Interconnectedness) } \\
\text { 2. Resource dimensions (Importance, } \\
\text { Discretion, Alternatives) }\end{array}$ \\
\hline \multirow[t]{2}{*}{$\begin{array}{l}\text { Economic } \\
\text { View }\end{array}$} & $\begin{array}{l}\text { Transaction } \\
\text { Cost }\end{array}$ & $\begin{array}{l}\text { Cost-efficiency } \\
\text { (Economics of } \\
\text { scale) }\end{array}$ & $\begin{array}{l}\text { Production cost, } \\
\text { Transaction cost }\end{array}$ & $\begin{array}{l}\text { 1. Asset specificity, } \\
\text { 2. Uncertainty, } \\
\text { 3. Infrequency }\end{array}$ \\
\hline & Agency Cost & $\begin{array}{l}\text { Principal-agent } \\
\text { relationship } \\
\text { (Contracts) }\end{array}$ & $\begin{array}{l}\text { Monitoring cost, } \\
\text { Bonding cost, } \\
\text { Residual loss cost }\end{array}$ & $\begin{array}{l}\text { 1. Uncertainty, 2. Risk aversion, } \\
\text { 3. Programmability, } \\
\text { 4. Measurability, } \\
\text { 5. Length of relationship }\end{array}$ \\
\hline \multirow[t]{2}{*}{ Social View } & $\begin{array}{l}\text { Power, } \\
\text { Political }\end{array}$ & $\begin{array}{l}\text { Power-structure } \\
\text { relationship }\end{array}$ & Power, Politic & $\begin{array}{l}\text { 1. Power (Authority, Resource acquisition, } \\
\text { Dependency \& low substitutability, } \\
\text { Uncertainty absorption) } \\
\text { 2. Politic (Selective use of decision criteria, } \\
\text { Selective use of information, Use of outside } \\
\text { Experts, Building coalitions, Cooptation) }\end{array}$ \\
\hline & $\begin{array}{l}\text { Social } \\
\text { exchange }\end{array}$ & $\begin{array}{l}\text { Interaction } \\
\text { processes }\end{array}$ & Trust, Culture & $\begin{array}{l}\text { 1. Comparison level, } \\
\text { 2. Comparison level for alternatives }\end{array}$ \\
\hline
\end{tabular}


i. Core Competencies Theory (Resource-Based Theory).

ii. Transaction Costs Theory

iii. Social view theory (Power, political and social exchange theory).

\section{Core competencies (resource based) theory}

Core competencies theory postulated that, the core activities should remain in house. It is a concept in management theory originally advocated by Prahalad and Hamel (1990). The concept of core competencies has been developed on the basis of the resourcebased theory. Prahalad and Hamel (1990) defined the core competencies as the collective learning in the organization, especially how to coordinate diverse production skills and integrate multiple stream technologies.

The main idea of this theory is enhancing the core competence of the company in order to develop sustainable competitive advantage, which outsourcing is positioned to achieve (Jae, et al. 2006). The resource-based view suggests that, valuable firm resources (comprising tangible and intangible elements) are usually scarce, imperfectly imitable, and lacking in direct substitutes; It is about producing the most value from one's existing capabilities and resources by combining these with others' sources of advantage and, in this, ensuring complementarities is paramount.

Some SMEs have some products that are peculiar and associated best with their organizations and this makes them to be regarded as leaders in the area of such product offerings or delivery to customers. A core competency can take various forms, including technical/subject matter know-how, a reliable process and/or close relationships with customers and suppliers (Jae, et al. 2006). It may also include product development or culture, such as employee dedication, best human resource management (HRM), good market coverage etc. Core competencies are particular strengths relative to other organizations in the industry which provide the fundamental basis for the provision of added value.

Due to the nature and minimal resource base of SMEs, especially in developing countries like Nigeria, such organizations turn to source for knowledge and expertise of outsiders who are not on their payroll to carry out activities such as back office (book keeping, payroll, order processing, other administrative services); Accounting services (financial reporting, tax processing); supporting activities (shipping, training) and even primary activities such as purchasing, manufacturing, warehousing, selling, customer service, others. This therefore points to the relevance of the resource based theory in general and core competency theory in particular in explaining the outsourcing decisions of SMEs.

However, there are instances where organizations may have the needed resources but still go ahead to outsource. Some even go to extent of subcontracting in areas of their core competence. This therefore brings the fore the insufficiency of the core competency theory in explaining the outsourcing decision in terms of strategic choice and implementation among SMEs.

\section{Transaction cost theory}

This theory holds an assumption that business outsourcing is implemented in order to lower the transaction costs. Transaction Cost Analysis (TCA) is another widely used outsourcing based theoretical perspective especially in supply chain management (Busi and McIvor, 2008). The approach seeks to identify the environmental factors that together with a set of related human factors explain how companies can organize transactions to reduce the costs 
associated with these transactions. TCA postulates that managers suffer from bounded rationality, whereas other stakeholders may opportunistically act if given the chance.

Small and medium scale enterprises are always out to minimize their cost of operation. They therefore subcontract some of their jobs which can be done more efficiently by outside vendors. This also paves way for them to enhance their customer service which leads to customer satisfaction.

This theory asserts that, an organization may outsource even when it has the wherewithal to execute the activity itself if and only if the sum cost carrying out the activity by an outside vendor including contract processing cost is lower than the cost of carrying out the activity in house. This theory is quite relevant in explaining the outsourcing of primary activities which are seen as being part of the organizations primary (core) operation as captured in their mission statement.

However, this theory cannot be said to be sufficient in explaining all outsourcing decisions of SMEs owing to the fact that some still go ahead to outsource even when they could have carried out the task cheaper than the outside vendor. This informed our decision to look at the social views.

\section{Social view theory}

Other researchers, especially in the marketing area, have suggested social theories such as social exchange theory and power-political theory as appropriate tools for analyzing the outsourcing relationships (Jae, et al. 2000). These theories are used to explain the reason why organizations enter into closer relationship with their service providers. They tried to understand the relationship as dynamic processes through specific sequential interactions in which two participants carry out activities toward one another and exchange valuable resources. Theories in the social aspect assume processes evolving over time as the actors mutually and sequentially demonstrate their trustworthiness whereas the exchange activities by the organizations in economic perspective are enforceable. Thus, the social theories are mainly used to explain partnership relationship between the clients and the service providers (Jae, et al. 2000).

Worthy of note here is the fact that some SMEs outsource their services to bigger organizations to attain recognition and or establish a relationship with a hope of other benefits rather than cost minimization such benefits may still lead to profit in later life of the business. Also, some organizations outsource their services just for patronage sake. Patronage here refers to social relationship without looking up for profit.

\section{Theory choice}

This research is based on the core competencies theory and the transaction cost theory which emphasizes minimization of cost either through concentrating on their core competences and subcontracting other non core areas of operation or subcontracting even their primary activities to others that can perform them less costly thereby earning some returns which is in form of the difference between the value of the contract and the cost of its execution. Cost here entails both; the amount paid the outsourcee and the processing/ operational fee. The choice of these two theories stems from the fact that, SMEs outsourcing entails both the core and non core activities. Social view theory is left out here for the thrust of this research is the effect of the strategies on profitability and not relatedness. The focus of every manager is achievement of objectives at a lesser cost. When one achieves a 
goal, the first question that comes to mind is how? How much was spent in realizing the goal? Is there any better way of doing it thereby incurring less cost? Outsourcing here is looked at as a "make or buy" decision where the decision maker looks at the cost of carrying out an activity and outsourcing it and goes for the more efficient one. This leads to achievement of customers' needs thereby attaining customer satisfaction at a lesser cost.

\section{Empirical review}

In a research to explore outsourcing strategies among small manufacturing firms, and to test how these strategies can be linked to financial performance (Return on Investment and Return on Equity), Isaksson and Lantz (2015) applied multiple regression on the data collected through a stratified sample of 700 small ( $<50$ employees) manufacturing firms in Sweden and realized that, there is no significant relationship between the strategies (Back office activities, Primary activities, Accounting activities, and Support activities) and financial performance measured in terms of return on investment (ROI) and return on equity (ROE). This research however, did not delve in the effect of these strategies on SMEs profitability. Also, the research was carried out in Sweden whose business environment is better established and so different from that of Nigeria.

To find out the strategies in the outsourcing process, the challenges associated with outsourcing in the hotel industry and what benefits are derived from outsourcing of non-core functions, Gyemang, Aikins, Asibey and Broni, (2014) used a descriptive approach to analyze and evaluate the impact of outsourcing in the hotel industry in Ghana. Questionnaires were administered to fifty (50) respondents comprising core management staff and other key heads of the departments and the main crew. At the end of the research, they concluded that, Hotels have been concentrating on their core functions in the areas of accommodation, food and bar services and housekeeping and have outsourced most of their non-core functions. This research was carried out with a very limited sample of only 50 respondents and also, did not point out clearly the various strategies embarked upon by the organizations.

To examine outsourcing services as a strategic tool for organizational performance in the Nigerian food, beverage, and tobacco industry, Suraju \& Hamed (2013) used two estimators: naïve estimator and the weighted estimator Proposed by Dehejia \& Wahba and modified by Nanfosso and Mbassi were used for the analysis. Data were obtained from the questionnaires administered for period of two weeks to cross-sections of 15 companies in food, beverage, and tobacco industry in Nigeria, as well as secondary data extracted from the files of statistical and fiscal declarations of these companies contained in the fact-book of Nigeria Stock Exchange (NSE) for the period of 2000-2010. At the end of the research, they realized that, the more an organization outsourced, the higher its organizational growth. Also, organizational productivity is positively correlated to the amelioration of competitive advantage of labor productivity and average production cost. The paper also revealed that outsourcing is beneficial to organizational performance, and enhances firm's financial economies and competitive advantage in the market place. This research considered outsourcing as a generic strategy instead of pointing out specific outsourcing strategies embarked upon by these organizations.

According to Yeboah (2013) who examined the relationship between outsourcing and organizational performance in the services sector using SPSS to correlate the variables and data gotten from a population of 50 firms operating in the banking and insurance sectors of the economy of Ghana reported that, there is no statistically significant 
correlation between outsourcing and organizational productivity, there is statistically significant correlation between outsourcing and quality, there is statistically significant correlation between outsourcing and competitive advantage. This research however fails to consider the effect of the strategy on organizational profitability.

To examine the axiomatic relationship between outsourcing strategy and organizational performance in Nigeria manufacturing sector, Akewushola, and Elegbede (2013) adopted a stratified sampling technique to arrive at 120 sample elements for the study. Some of the top and middle level managers of Cadbury Nigeria Plc and Nestle Foods Plc responded to the questionnaire administered and were interviewed to further elicit information on the key variables. Data obtained were analyzed using Regression analysis, the researchers realized that, firms that outsource experience reduced average cost, increased sales turnover and profitability, enhance expertise, improve service quality, reduce staff strength, streamline the production process, reduced administrative burden and save time for core activities. This research however, is limited to the manufacturing sector of Nigeria.

To ascertain the effect of outsourcing strategy on project success, Irefin, et al. (2012) administered copies of questionnaire to staff of Nestle Nigeria PLC using stratified sampling techniques and also interviewed some to authenticate the information derived. Data obtained was analyzed using frequency distribution and Chi-Square analysis. The research found out that, Firms outsourced their production process in order to manage cost, reduce time-to-market, boost bottom line, increase sales turnover and profitability, enhance expertise, improve service quality, reduce staff, streamline the process, reduce the administrative burden and save time for core activities. This research gives a very good background for the assessment of the effect their outsourcing activities had had on the performance of their enterprises.

To examine the propensity to outsourcing and its impacts on operational objectives including cost reduction, improved quality, flexibility and better service and organizational performance, which includes financial performance and non-financial performance, Nazeri, et al. (2012) analyzed feedback of questionnaires distributed among the board of directors, quality managers, operational administrators, and lower managers using SPSS and Minitab software based on deductive and descriptive statistics. The results of the survey indicated that outsourcing could lead to reduced cost, improve quality, increase flexibility, better financial and non-financial performance and services.

To examine the relationship between the outsourcing process, and perceived organizational performance, Bolat and Yilmaz (2009) surveyed Eighty (80) hotels in Turkey and realized that, Outsourcing has a positive effect on organizational performance (organizational effectiveness, productivity, profitability, quality, continuous improvement, quality of work life, and social responsibility levels).

To examine the impact of outsourcing on a firm's performance, Jiang et al. (2006) used annual report data from a sample of 51 publicly traded firms in USA and got some evidence that outsourcing improved firm's cost-efficiency (sales less expenses/sales) but did not find any effect on firm's productivity or profitability (ROA and profit margin). This research was carried out in a developed country/economy setting; also, using firms that are not clearly defined as being in the small scale category. This research can therefore serve only as a background for a research on SMEs in a developing country/economy.

To analyze the effect of outsourcing of human resource (HR) activities (payroll and training outsourcing) on firm performance, Gilley et al. (2004) sampled 94 manufacturing firms in U.S.A and found out that, outsourcing had no effect on financial 
performance, but there was a small positive effect on firm's innovation performance (R\&D outlays, process innovation and product innovations) and stakeholder performance (employment growth \& morale, customer and supplier relations). This research was also carried out in a developed nation as such serves as a background for this research.

As noted here, previous research findings have proved contradictory results on the effect of outsourcing strategy on performance. While some including those of Gyemang, et al. (2014); Suraju \& Hamed (2013); Akewushola, and Elegbede (2013); Irefin, Olateju, \& Hammed (2012); Awolusi (2012); Nazeri, Gholami \& Rashidi (2012); Hayes, et al. (2000), presented a positive effect, those of Isaksson \&Lantz (2015); Yeboah (2013) and Gilley, et al. (2004); found out no effect or relationship between outsourcing and performance. Also, Most of the research were carried out in relatively strong economies and developed nations and so, their findings cannot be imported directly and said to represent what is obtainable in a developing country/economy like Nigeria. The gap is further buttressed in the following section.

\section{Research gap and statement of hypotheses}

From the concepts reviewed, outsourcing strategies of SMEs can be measured in terms of outsourcing of back office activates, primary activities, accounting activities and support activities (Gilley and Rasheed, 2000; Isaksson and Lantz, 2015). SMEs performance on the other hand can be measured (in addition to others) in terms of profitability (Malhorta, 1997; Carney, 1997; and Goldstein, 1999). In terms of theoretical backing, several researchers have adopted the core competency theory which emphasized the outsourcing of functions which are outside of a firm's core area of operation. This is also true for SMEs for due to their minimal resource base, especially in developing countries like Nigeria, these organizations turn to source for knowledge and expertise of outsiders who are not on their payroll. This buttresses the choice of this theory to explain the outsourcing of back office activities, accounting activities and support activities.

However, it falls short in explaining the outsourcing of the core areas by SMEs. There are instances where organizations may have the needed resources but still go ahead to outsource. This informs the relevance of the transaction cost theory. This theory asserts that, an organization may outsource even when it has the wherewithal to execute the activity itself if and only if the sum cost carrying out the activity by an outside vendor including contract processing cost is lower than the cost of carrying out the activity in house. This theory is quite relevant in explaining the outsourcing of primary activities which are seen as being part of the organizations primary (core) operation as captured in their mission statement. In line with the theory choice here, where the core competency theory explains in part as augmented by the transaction cost theory which explains the outsourcing of primary activities, a research is needed to assess the effect of these outsourcing strategies on the profitability of organizations (SMEs) who operate in an environment where profitability is emphasized.

In terms of empirical studies, the researches reviewed herein and several others consulted did not show clearly how various outsourcing strategies affect the performance of SMEs in terms of profitability and also in a developing country environment like that of Nigeria. For instance, Gyemang, et al. (2014) carried out their research using hotel industry in Ghana with a very limited sample of only 50 respondents and also, did not point out clearly the various strategies embarked upon by the organizations; Suraju \& Hamed (2013)'s research considered outsourcing as a generic strategy instead of pointing 
out specific outsourcing strategies embarked upon by these organizations; Akewushola, and Elegbede (2013) limited theirs to the manufacturing sector of Nigeria and also did not specially outline and assessed the effect of various strategies on SMEs profitability.

The research by Isaksson and Lantz, (2015) is very pertinent here. It is Isaksson and Lantz, (2015) who did a study on the specific outsourcing strategies and their effect on SMEs financial performance. This research however, was done measuring financial performance in terms of return on investment (ROI) and return on equity (ROE) leaving out profitability which is the main focus of most SMEs businesses. SMEs, especially in developing countries like Nigeria, focuses on their profitability and so measures their successes primarily based on the difference between the money spent on a project and that realized. This informs the essence of replicating such a research in Nigeria and also focusing on profitability rather than other performance measures. This has created a gap which this research sought to fill. The research therefore made the following hypotheses:

$\mathrm{Ho}_{1}$ Outsourcing of Back Office Activities has no significant effect on the profitability of SMEs in Nigeria

$\mathrm{Ho}_{2}$ Outsourcing of Primary Activities has no significant effect on the profitability of SMEs in Nigeria

$\mathrm{Ho}_{3}$ Outsourcing of Accounting Activities has no significant effect on the profitability of SMEs in Nigeria

$\mathrm{Ho}_{4}$ Outsourcing of Support Services has no significant effect on the profitability of SMEs in Nigeria

\section{Model conceptualization and specification}

\section{Diagrammatical model}

Figure 3 shows the link between outsourcing strategies which when embarked upon by the SMEs lead to organizational performance. The outsourcing strategies as captured by the diagram are outsourcing of back office activities, primary activities, accounting activities and support activities. These outsourcing activities when carried out by SMEs as shown by the link between the various strategies and SMEs organization leads to a performance which here is defined in terms of profitability.

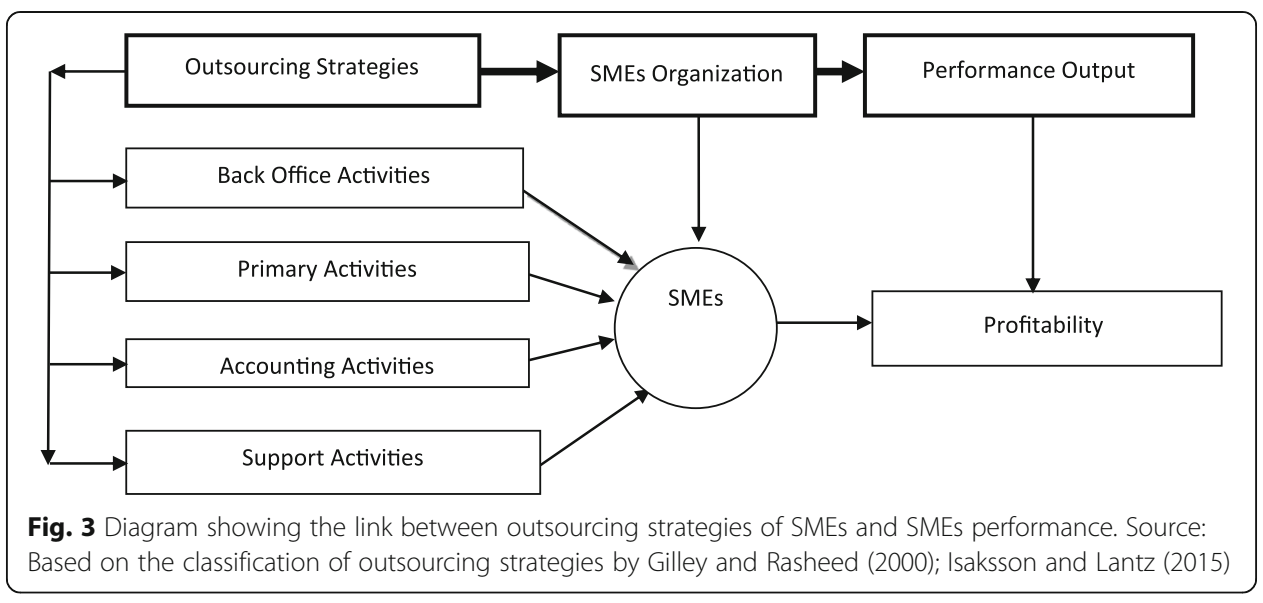




\section{Mathematical model}

Multiple regression with profitability as dependent variable is conducted with the four outsourcing strategies as explanatory variables while simultaneously controlling for enterprise size and strategic direction. Thus, the generic model is given as:

$$
\text { Perf } .=f(\text { Outs })
$$

Where:

Perf $=$ performance

Outs = outsourcing Strategy

The specified regression model to be tested is:

$$
\begin{aligned}
\text { Prof }= & b_{0}+b_{1} B O F+b_{2} P R I+b_{3} A C C+b_{4} S U P+b_{5} S T R+b_{6} N O E+b_{7} Y R S \\
& +b_{8} S O P+b_{9} O N S+b_{10} A S S+\varepsilon
\end{aligned}
$$

Where:

Prof $=$ Profitability (measured by cost savings, focus on core business, reduction in money spent on fixed assets (cost restructuring), reduction in tax paid (tax benefit)) $B O F=$ Back Office activities (measured by the average tendency of outsourcing back office activities)

$P R I=$ Primary Activities (measured by the average tendency of outsourcing primary activities)

$A C C=$ Accounting Activities (measured by the average tendency of outsourcing accounting activities)

SUP = Supporting activities (measured by the average tendency of outsourcing support activities)

STR (control variable) = a dummy variable describing whether the core company strategy should be described as oriented towards costs (value $=1$ ) or differentiation (value $=0$ ) NOE (control variable) $=$ a dummy variable describing the number of employees of a SMEs $Y R S$ (control variable) $=$ a dummy variable describing the number of years a SMEs has been in operation

SOP (control variable) $=$ a dummy variable describing SMEs sector of operation ONS (control variable) = a dummy variable describing SMEs ownership structure ASS (control variable) = a dummy variable describing SMEs value of assets $\varepsilon=$ the error term of $5 \%$ which is provided for in the course of the analysis. The a priori expectations are:

$$
\mathrm{b}_{1}, \mathrm{~b}_{2}, \mathrm{~b}_{3}, \mathrm{~b}_{4}, \mathrm{~b}_{5}, \mathrm{~b}_{6} \mathrm{~b}_{7} \mathrm{~b}_{8} \mathrm{~b}_{9} \mathrm{~b}_{10}>1
$$

\section{Methods}

The specification of relevant procedures for collecting and analysing information (data) which would help solve the research problem at hand is quite pertinent for a research (Agburu, 2007). For the purpose of this study, survey research design and secondary data was adopted. Thus, data was collected through the use of questionnaire (which entails going to the field to source for responses from experts and other respondents). 
Also, a secondary data source was used which contains the relevant data about outsourcing strategies and also, profitability of some selected SMEs.

To source for primary data, the researchers sought the responses of SMEs located in Gboko, Makurdi and Otukpo metropolis which are the three major towns in Benue State. Based on the records for year 2014 gotten from Benue state Board of Internal Revenue Service (BIRS), the researcher arrived at a target population of five hundred and sixty three (563) which consists of SMEs operating in the selected metropolis. From the population of 563, a sample of 233 SMEs was selected using Taro Yamane's formula for sample determination as follows:

$$
\mathrm{n}=\mathrm{N} / 1+\mathrm{N}(\mathrm{e})^{2}
$$

Where: $\mathrm{n}$ = sample size; $\mathrm{N}$ = population size; $\mathrm{e}=$ level of significance; 1 and 2 are constants.

$$
\begin{aligned}
& \mathrm{n}=563 / 1+563(0.05)^{2} \\
& \mathrm{n}=563 / 1+1.4075 \\
& \mathrm{n}=233
\end{aligned}
$$

The sample size as calculated above is 233 SMEs and is shared among the three selected towns under study using Bourley's 1994 population allocation formula in Nzelibe and Ilogu (1999, p.201) as stated below:

$$
\mathrm{nS}=\frac{\mathrm{n}(\mathrm{NS})}{\mathrm{N}}
$$

Where: $\mathrm{nS}=$ sample size per town; $\mathrm{n}=$ total sample size; $\mathrm{NS}=$ Total number of SMEs in the area of study; $\mathrm{N}=$ Total population size. This results in the sampling of 69 SMEs in Gboko, 105 from Makurdi and 59 from Otukpo metropolis. For a population that is made up of sub groups, a stratified random sampling can be used in drawing a sample (Orsaah, 2009). The sample size was therefore shared among six categories of SMEs purposively selected for using stratified random sampling technique where the proportions are taken based on their existence in the population. The categories, their proportions and the number sampled using Bourley's 1994 formula are shown in Table 2.

From Table 2, the sample distribution as calculated using Bourley/s formula shows proportionately the number sampled as 22 for manufacturing, 33 for educational, 5 for computer/information technology and telecommunication, 43 for restaurants and hotels and 130 for wholesale and retail shops. The questionnaires were therefore purposely distributed to SMEs in the three selected town for they are seen as been homogenous regardless of their location in the state.

A questionnaire was administered on every SMEs sampled whereby either the owner, manager (or a top officer) responded to it. This was done through personal delivery. That notwithstanding, ten (10) SMEs (two each from the five areas of operation under study), were sampled for secondary data to confirm the responses of various SMEs.

To ensure validity of the measuring instruments in this research, a carefully drafted and wide-ranging questionnaire aimed at eliciting right responses was constructed and piloted in order to detect any ambiguities or inherent problems. While some questions were open-ended most were with a response scale of 1 to 5 . The questionnaire is designed to capture detailed profile of the respondents in addition to what they consider as their outsourcing of core activities and its effect on their performance. Also, expert 
Table 2 Sample Distribution

\begin{tabular}{lll}
\hline Area of operation/ Nature of business & $\begin{array}{l}\text { Number of SMEs in } \\
\text { the population }\end{array}$ & $\begin{array}{l}\text { Number sampled } \\
\mathrm{nS}=\frac{\mathrm{n}(\mathrm{NS})}{\mathrm{N}}\end{array}$ \\
\hline $\begin{array}{l}\text { 1. Manufacturing } \\
\text { 2. Educational }\end{array}$ & 52 & $\frac{233(52)}{563}=22$ \\
$\begin{array}{l}\text { 3. Computer/Information Technology } \\
\text { \& Telecommunication }\end{array}$ & 12 & $\frac{233(80)}{563}=33$ \\
$\begin{array}{l}\text { 4. Restaurants and Hotels } \\
\text { 5. Wholesale and retail shops }\end{array}$ & 105 & $\frac{233(12)}{563}=5$ \\
Total & 314 & $\frac{233(105)}{563}=43$ \\
\hline
\end{tabular}

Source: Field Survey, (2017)

opinions on the subject were sought to confirm the extent to which the question has face and content validity.

To ensure reliability, this research used Cronbach alpha coefficient to test reliability. The Cronbach's coefficient alpha ranges from 0 to 1 . A scale is considered to have good reliability if it has an alpha value greater than 0.60 (Zikmund, 2010). The Cronbach's alpha results were 0.761 for outsourcing of Back Office Activities, 0.721 for outsourcing of primary activities, 0.701 for outsourcing of accounting activities, .743 for outsourcing of supporting activities, 0.843 for organizational performance, while the overall alpha coefficient is 0.929 .

Hypotheses were tested using multiple regression analysis. The output shows the tstatistic and $p$-values for the coefficients which results in either rejecting or accepting the hypotheses at a specified level of significance. The null hypothesis is rejected where the $p$-value is less than the critical value (0.05). Also, the output shows the coefficient of determination $\left(\mathrm{r}^{2}\right)$, which measures the proportion of the dependent variable that is explained by the regression model. The range for the coefficient of determination varies between 0 and 1 ; that is $0 \leq \mathrm{r}^{2} \leq 1$. As $\mathrm{r}^{2}$ approaches 1 , the more the independent variable explains the variation in the dependent variables. Statistical Package for Social Sciences (SPSS 20.0) computer program was used to enhance the robustness of the results.

\section{Results and discussion}

\section{Results of questionnaire}

A total of 233 questionnaires, each containing 18 aggregate questions were designed and issued out to respondents who are divided into 5 categories of SMEs base on their area of operations. At the end of the questionnaire process which took place from 10th January, 2017 to 15th March, 2017, only 218 representing 93.5\% of questionnaires were dully filled devoid of errors and returned to the researcher and so, the analysis of questionnaire responses was based on these 218 copies dully returned.

\section{Demographic characteristics of respondents}

Demographic content here entails the distribution of respondents (SMEs) based on area/ nature of operation, nature of ownership, duration of operation (in years), 
number of employees, worth including working capital but excluding value of land and annual turnover. The detail of these attributes is captured in Table 3.

Result from Table 3 presents in addition to others, the area of operation distribution of respondents. Out of the 218 respondents, 20 (9.17\%) are into manufacturing; 28 (12.84\%) are owners/operators of schools; 5 representing $2.29 \%$ are into computer/ information technology \& telecommunication; also, another 41 (18.81\%) are operators of restaurants and hotels while the remaining 124 (56.88\%) are operators of wholesale and

Table 3 Respondent's Distribution based on SMEs' Characteristics

\begin{tabular}{|c|c|c|}
\hline Attribute & Frequency & Percentage (\%) \\
\hline \multicolumn{3}{|l|}{ Area of operation/Nature of business: } \\
\hline Manufacturing & 20 & 9.17 \\
\hline Educational & 28 & 12.8 \\
\hline Computer/information technology and communication & 5 & 2.29 \\
\hline Restaurants and hotels & 41 & 18.18 \\
\hline Wholesale and shops & 124 & 56.88 \\
\hline Total & 218 & 100 \\
\hline \multicolumn{3}{|l|}{ Nature of Ownership: } \\
\hline Private limited company & 13 & 5.96 \\
\hline Public limited company & - & - \\
\hline Partnership & 47 & 21.56 \\
\hline Sole proprietorship & 136 & 62.39 \\
\hline Family owed & 22 & 10.09 \\
\hline Others & - & - \\
\hline Total & 218 & 100 \\
\hline \multicolumn{3}{|l|}{ Duration of operation: } \\
\hline Less than 5 years & 15 & 6.88 \\
\hline Between 5 and 10 years & 162 & 74.31 \\
\hline Between 11 and 15 years & 20 & 9.17 \\
\hline Between 16 and 20 years & 5 & 2.29 \\
\hline Above 20 years & 16 & 7.34 \\
\hline Total & 218 & 100 \\
\hline \multicolumn{3}{|l|}{ Number of employees: } \\
\hline Less than 50 employees & 197 & 90.37 \\
\hline Between 50 and 100 employees & 21 & 9.63 \\
\hline Total & 218 & 100 \\
\hline \multicolumn{3}{|l|}{ Worth including working capital but excluding value of land: } \\
\hline Less than 10 million naira & - & - \\
\hline Between 10 million and 100 million naira & 186 & 89.91 \\
\hline Between 101 million and 300 million naira & 22 & 10.09 \\
\hline Total & 218 & 100 \\
\hline \multicolumn{3}{|l|}{ Annual Turnover: } \\
\hline 10 million Naira and below & 146 & 66.97 \\
\hline \multicolumn{3}{|l|}{ Over 10 million naira but not more } \\
\hline than 20 Million Naira & 72 & 33.06 \\
\hline Total & 218 & 100 \\
\hline
\end{tabular}

Source: Survey data (2017) 
retail shops. The distribution is uneven and commensurate with the proportion of the areas of operation in the sample.

The nature of ownership of the SMEs is also captured in Table 3. Results captured shows that, out of the 218 respondents, 13 (5.96\%) are private limited companies, none is a public limited company, $47(21.56 \%)$ are partnership ventures, 136 representing $62.39 \%$ are of sole ownership, while the remaining $22(10.09 \%)$ are family owned. This unveils the nature of SMEs ownership in Nigeria where the majority is solely owned.

From Table 3, out of the 218 organizations, only 15 (6.88\%) has been in operation for less than five years. Those that have been in operation between 5 and 10 years are 162 (74.31\%). Also, those that have been in operation between 11 and 15 years are 20 (9.17\%). Those that have been in operation between 16 and 20 years are $5(2.29 \%)$, whereas, those in operation for over 20 years are 16 representing (7.34\%). By definition of SMEs and the nature of businesses in Nigeria where most start small, most of the business surveyed had been in business for about five years.

Also, from Table 3, out of the 218 organizations, those with staff strength of less than 50 employees are 197 (90.37\%), whereas, those with staff strength between 50 and 100 are $21(9.63 \%)$. This means that, most of the enterprises surveyed are small scale and just few are of medium scale. This is also in line with the fact that, just few of the enterprises in the country are not small scale.

The distribution of questionnaires base on SMEs' worth including working capital but excluding value of land is also shown in Table 3. From Table 3, out of the 218 organizations, those between 10 million and 100 million naira are 196 (89.91\%) and the remaining 22 (10.09\%) falls between 101 million and 300 million naira. This unveils the capital and assets base of SMEs in Nigeria where most are are within the small scale range where there worth is below 100 million naira.

Finally, Table 3 shows that, SMEs with annual turnover of 10 million naira and below are $146(66.97 \%)$ whereas, the remaining $72(33.03 \%)$ are those with a turnover of over 10 million naira but not more than 20 million naira. This shows the operational nature in terms of turnover and points to the fact that, most of the enterprises surveyed are worth just about 10 million naira in annual revenue.

\section{Respondent's views about the outsourcing (subcontracting) of one or more activities}

The views of respondents about the outsourcing of back office activities, primary activities, accounting activities and support activities are presented in Table 4.

From Table 4, the summary of respondent's views about the outsourcing (subcontracting) of one or more of back office activities such as security services, cleaning services, bookkeeping, payroll, billing, order processing, payment processing, others are categorized based on SMEs area of operation. The distribution revealed that 34 (16\%) respondents strongly disagreed to the assertion that they have outsourced supporting activities within the past five years. Also, 67 (31\%) disagreed while 37 (17\%) are neutral. However, 38 (17\%) agreed to the assertion that they have outsourced supporting activities within the past five years. Also 42(19\%) strongly agreed. This result shows that, not all SMEs outsource their back office activities; only a small percentage does.

Average responses on areas of outsourcing grouped under primary activities as shown in the results from Table 4 revealed that 54 (25\%) respondents strongly disagreed to the 
Table 4 Summary of Respondent's Views about the Outsourcing (Subcontracting) of one or more Activities

\begin{tabular}{|c|c|c|c|c|c|c|}
\hline Attribute & SD & $\mathrm{D}$ & $\mathrm{N}$ & A & SA & Total \\
\hline \multicolumn{7}{|l|}{ Back office activities: } \\
\hline Manufacturing & 8 & 5 & 3 & 3 & 1 & 20 \\
\hline Educational & 10 & 8 & 4 & 4 & 2 & 28 \\
\hline Computer/ Information and Telecommunication & 1 & 1 & 1 & 1 & 1 & 5 \\
\hline Restaurants and hotels & 3 & 5 & 2 & 12 & 19 & 41 \\
\hline Wholesale and retail shops & 12 & 48 & 27 & 18 & 19 & 124 \\
\hline Total Average Response & 34 & 67 & 37 & 38 & 42 & 218 \\
\hline Average Percentage (\%) & 16 & 31 & 17 & 17 & 19 & 100 \\
\hline \multicolumn{7}{|l|}{ Primary Activities: } \\
\hline Manufacturing & 2 & 3 & 5 & 6 & 4 & 20 \\
\hline Educational & 4 & 5 & 5 & 8 & 6 & 28 \\
\hline Computer/ Information Technology & .2 & .5 & 2 & 1.5 & .8 & 5 \\
\hline Restaurants and hotels & 14.5 & 14 & 5.8 & 5 & 1.7 & 41 \\
\hline Wholesale and Retail Shops & 33 & 62.5 & 18 & 7 & 3 & 124 \\
\hline Average Response & 54 & 85 & 36 & 28 & 15 & 218 \\
\hline Average Percentage (\%) & 25 & 39 & 16 & 12 & 7 & 100 \\
\hline \multicolumn{7}{|l|}{ Accounting activities: } \\
\hline Manufacturing & 2 & 3 & 3 & 5.5 & 6.5 & 20 \\
\hline Educational & 8 & 8.5 & 5.5 & 5 & 1 & 28 \\
\hline Computer/ Information Technology & 1 & 1 & 1 & 1 & 1 & 5 \\
\hline Restaurants and hotels & 2 & 3.5 & 6.5 & 10.5 & 18.5 & 41 \\
\hline Wholesale and Retail Shops & 8.5 & 7.5 & 22.5 & 17 & 67.5 & 124 \\
\hline Average Response & 22 & 24 & 39 & 28 & 94 & 218 \\
\hline Average Percentage (\%) & 10 & 11 & 18 & 18 & 43 & 100 \\
\hline \multicolumn{7}{|l|}{ Supporting activities: } \\
\hline Manufacturing & 2.8 & 3.7 & 2.7 & 4.5 & 6.3 & 20 \\
\hline Educational & 1.7 & 4 & 4.7 & 9 & 8.7 & 28 \\
\hline Computer/ Information Technology & 1.1 & 0.5 & 1.3 & 1.5 & 0.5 & 5 \\
\hline Restaurants and hotels & 2.3 & 4.5 & 3 & 11.7 & 19.5 & 41 \\
\hline Wholesale and Retail Shops & 2.7 & 3.8 & 7.2 & 67.7 & 39.3 & 124 \\
\hline Average Response & 11 & 17 & 19 & 94 & 74 & 218 \\
\hline Average Percentage (\%) & 5 & 8 & 7 & 43 & 34 & 100 \\
\hline
\end{tabular}

Source: Survey Result, (2017)

assertion that they have outsourced primary activities within the past five years. Also, 85 (39\%) disagreed while $36(16 \%)$ are neutral. However, 28 (12\%) agreed to the assertion that they have outsourced supporting activities within the past five years. Also 15 (7\%) strongly agreed. This result shows that only few SMEs outsource their primary activities.

Also, from Table 4, on average, $22(10 \%)$ respondents opined strongly that they do not outsource their accounting services. 24 (11\%) also disagreed whereas, $39(18 \%)$ are neutral. However, 39 (18\%) agreed and 95 (43\%) strongly agreed. This result shows that, most SMEs outsource some of their accounting activities. However, the sector evidence shows that, whole sale and retail shops which forms the bulk of the sample outsources much of their accounting services and this leads to the high average 
percentage so recorded even though, some educational services hardly outsource their accounting services.

Finally, average responses on areas of outsourcing grouped under supporting activities as shown in Results from Table 4 revealed that 11 (5\%) respondents strongly disagreed to the assertion that they have outsourced supporting activities within the past five years. Also, 17 (8\%) disagreed while 19 (7\%) are neutral. However, 94 (43\%) agreed to the assertion that they have outsourced supporting activities within the past five years. Also 74 (34\%) strongly agreed. These responses point to a fact that, most SMEs outsource their support services. The outsourcing of services which are of support nature forms the bulk of their outsourcing practice.

\section{Respondent's views about their profitability as it relates to the outsourcing (subcontracting) of one or more of outsourcing activities}

The views of respondents based on the profitability of SMEs relating to their outsourcing of one or more activities are shown in Table 5.

From Table 5, an average respondents of $11(5 \%)$ strongly disagreed that outsourcing leads to their profitability. About $8 \%$ representing 18 respondents also disagreed while 27 (12\%) respondents stood undecided. However, 102 (47\%) respondents agreed that their outsourcing activities have led to their profitability. Also, an average of 61(28\%) strongly agreed. This clearly shows that, SMEs are of the opinion that, their outsourcing practice has over the years resulted in increased profitability. Due to the nature of their accounting systems which are unsophisticated and so basically captures their expenses and returns, SMEs profitability here as reported may be only the difference between the amount spent in the subcontracting process and that realized in return. This however points to the fact that, outsourcing strategies embarked upon by SMEs has an effect on their profitability.

\section{Regression result for questionnaire responses}

Table 6 shows the results from the multiple regression analysis with profitability as dependent variable and the outsourcing strategies as explanatory variables. From the regression result, $F(4,218)=102.032$ at a 0.00 level of significance while $R^{\wedge} 2=0.596$ which is the coefficient of determination which measures the proportion of the dependent variable that is explained by the regression model. It points that the regression model explains up to $59.6 \%$ of the dependent variable.

Table 5 Summary of Respondent's Views about their Profitability as it Relates to the Outsourcing (Subcontracting) of one or more of Outsourcing Activities

\begin{tabular}{lllllll}
\hline Area of operation/ Nature of business & S D & D & N & A & SA & Total \\
\hline Manufacturing & 2 & 3 & 2.8 & 7 & 5.6 & 20 \\
Educational & 1.6 & 3 & 3.4 & 10 & 10 & 28 \\
Computer/ Information Technology \& Telecommunication & - & 1 & 1.2 & 1.8 & 1 & 5 \\
Restaurants and Hotels & 2 & 3.8 & 3.2 & 10.8 & 21.4 & 41 \\
Wholesale and retail shops & 5.6 & 7.2 & 16 & 72.8 & 22.8 & 124 \\
Total Average response & 11 & 18 & 27 & 102 & 61 & 218 \\
Average percentage (\%) & 5 & 8 & 12 & 47 & 28 & 100 \\
\hline
\end{tabular}

Source: survey data,(2017) 
Table 6 Effect of Outsourcing Strategies on SMEs Profitability (based on questionnaire responses)

\begin{tabular}{lllll}
\hline Model & B & Std. Error & T & $p$-value \\
\hline Outsourcing of Back Office Activities & .199 & .054 & 3.724 & .000 \\
Outsourcing of Primary Activities & .247 & .060 & 4.133 & .000 \\
Outsourcing of Accounting Activities & .018 & .060 & .295 & .768 \\
Outsourcing of Supporting Activities & .108 & .046 & 2.354 & .019 \\
\hline
\end{tabular}

From the test of hypotheses in Table 7, the acceptance/rejection decision is taken base on the decision rule that states that, the null hypothesis will be rejected if the $p$-value (Sig.) is less than the critical value (0.05). The detail of the regression result is attached as appendix IV. Based on the decision rule therefore, the results in Table 7 show that:

1. Outsourcing of Back Office Activities has a significant effect on the profitability of SMEs in Nigeria

2. Outsourcing of Primary Activities has a significant effect on the profitability of SMEs in Nigeria

3. Outsourcing of Accounting Activities has no significant effect on the profitability of SMEs in Nigeria

4. Outsourcing of Support Services has a significant effect on the profitability of SMEs in Nigeria

\section{Results of secondary data}

The estimated cost of outsourcing based on various outsourcing strategies of ten (10) selected SMEs and their estimated profits for the period under consideration (2012-2016) are presented and regressed to arrive at the effect of various outsourcing strategies on the organizations' profitability. Here two organizations are selected each from the five areas of operation considered in the research. Table 8 below shows the estimated profits of selected SMEs.

\section{Regression result of secondary data}

From the regression results above, $F(4,49)=43.760$ at a 0.00 level of significance while $\mathrm{R}^{\wedge} 2=.795$ which is the coefficient of determination which measures the proportion of the dependent variable that is explained by the regression model. It points that the regression model explains up to $79.5 \%$ of the dependent variable.

From the test of hypotheses, the acceptance/rejection decision is taken base on the decision rule that states that, the null hypothesis will be rejected if the p-value (Sig.) is less than the critical value (0.05). The detail of the regression result is attached as appendix V. Just like in the case of primary data, based on the decision rule therefore, the results in Table 9 show that:

Table 7 Test of Hypotheses

\begin{tabular}{lllll}
\hline S/N & Model & $T$ & $p$-value & Decision \\
\hline 1 & Outsourcing of Back Office Activities & 3.724 & .000 & Rejected \\
2 & Outsourcing of Primary Activities & 4.133 & .000 & Rejected \\
3 & Outsourcing of Accounting Activities & .295 & .768 & Accepted \\
4 & Outsourcing of Supporting Activities & 2.354 & .019 & Rejected \\
\hline
\end{tabular}


Table 8 Effect of outsourcing strategies on SMEs profitability (based on estimated annual profits)

\begin{tabular}{lllll}
\hline & B & Std. Error & T & $p$-value \\
\hline Estimated Cost of Outsourcing Back Office Activities & 36.352 & 9.579 & 3.795 & .000 \\
Estimated Cost of Outsourcing Primary Activities & -39.093 & 6.577 & -5.944 & .000 \\
Estimated Cost of Outsourcing Support Activities & 33.602 & 15.533 & 2.163 & .036 \\
Estimated Cost of Outsourcing Accounting Activities & 19.825 & 10.155 & 1.952 & .057 \\
\hline
\end{tabular}

1. Outsourcing of Back Office Activities has a significant effect on the profitability of SMEs in Nigeria

2. Outsourcing of Primary Activities has a significant effect on the profitability of SMEs in Nigeria

3. Outsourcing of Accounting Activities has no significant effect on the profitability of SMEs in Nigeria

4. Outsourcing of Support Services has a significant effect on the profitability of SMEs in Nigeria

\section{Discussion of findings}

Findings about hypothesis one which is in line with objective one:

This hypothesis states that Outsourcing Back Office Activities has no significant effect on the performance of SMEs in Nigeria. The performance measure here is profitability.

Based on the regression result for secondary data (Sig. 0.000) as backed by the result of respondents' views $(p=0.000)$, the alternative hypothesis was accepted which says that there is a significant relationship between outsourcing of back office activities and performance of SMEs in Benue state, Nigeria. From the responses gotten through the questionnaire, this research found out that, SMEs outsource back office activities such as, security services, cleaning services, bookkeeping services, order processing and other administrative services. Giving out these services to outside vendors who can perform them better has also resulted in a decrease in the cost of running the enterprises. Giving out theses services which are practically augmenting in nature also paves way for the enterprises to focus on their core areas and so enjoy the benefits of specialization.

This finding supports the view by, Lau and Hurly (1997), Kotabe et al. (1998), Frayer et al. (2000), Gupta and Zheuder (1994), Greer et al. (1999), others that outsourcing is correlated to profitability through cost savings, focus on core businesses, cost restructuring, tax benefits and increase turnover. This finding however, opposes the finding by Isaksson and Lantz (2015) which asserts that outsourcing strategies and outsourcing of back office activities to be specific has no significant effect on financial performance of SMEs as shown by their research in Sweden. Isaksson and Lantz (2015) measured financial performance in terms of ROI and ROE and found no effect where as our research

Table 9 Test of Hypothesis

\begin{tabular}{lllll}
\hline S/N & Model & $T$ & $p$-value & Decision \\
\hline 1 & Outsourcing of Back Office Activities & 3.795 & .000 & Rejected \\
2 & Outsourcing of Primary Activities & 5.944 & .000 & Rejected \\
3 & Outsourcing of Accounting Activities & 1.952 & .057 & Accepted \\
4 & Outsourcing of Supporting Activities & 2.163 & .036 & Rejected \\
\hline
\end{tabular}


measured financial performance in terms of profitability which merely considered the difference between the cost of outsourcing and the return realized. The difference in our result may not be unconnected with the difference in our measure of performance. This finding further supports resource-based thinking which as postulated by CK Prahalad and Gary Hamel stipulate that firms benefit more when resources are channeled towards core activities while the non core activities such as back office activities are contracted to an outside vendor (Prahalad \& Hamel, 1990).

\section{Findings about hypothesis two which is in line with objective two:}

This hypothesis states that, Outsourcing Primary Activities has no significant effect on the performance of Small and medium scale enterprises in Nigeria.

Base on the regression result for secondary data (Sig. 0.000) as backed by the result of respondents' views $(p=0.000)$ which fully supports the alternative view, the alternative hypothesis was accepted which says that there is a significant relationship between outsourcing of primary activities and performance of SMEs in Nigeria. The findings reveal that, there is an effect of outsourcing primary activities such as manufacturing, purchases, warehousing, sales force, and customer service, others on the profitability of SMEs. The findings show a very strong effect of this outsourcing strategy on SMEs financial performance.

This finding however opposes the thinking of proponents of core competency theory which stresses that the primary activities which fall within the core area of operation of organizations should be retained in house and so carried out by the organization itself. Rather, it supports the transaction cost theory which emphasizes more on the cost of operation and so states that, organizations should contract or subcontract their operations if such can be done cheaper and or better by an outside vendor (Yalokwu, 2006). SMEs due to their profit focused nature turn to go buy in any strategy that will increase their returns, as such outsource even their primary activities when they are convinced that the outside vendor can do it cheaper and or better.

Just like in the case of back office activities aboe, this finding supports the view by, Lau and Hurly (1997), Kotabe et al. (1998), Frayer et al. (2000), Gupta and Zheuder (1994), and Greer et al. (1999) but opposes the finding by Jiang et al. (2006) and Isaksson and Lantz (2015) which found no effect of outsourcing primary activities on financial performance of SMEs. In the same way, the difference in result here is as a result of difference in measure of performance. Also, the level of outsourcing in primary activities done in a relatively low economic country like Nigeria is higher than that of Sweden.

\section{Findings about hypothesis three which is in line with objective three:}

This hypothesis states that, Outsourcing Accounting Activities has no significant effect on the performance of Small and medium scale enterprises in Nigeria.

Here, based on the result of both regression analyses, which are greater than the critical value of 0.05 ( $p=0.768$ and $p=.057$ for primary and secondary data respectively), the null hypothesis was accepted which supports the assertion by Isaksson and Lantz (2015) that outsourcing strategies and outsourcing of primary activities to be specific has no significant effect on financial performance of SMEs as shown by their research in Sweden. The result here means that, Outsourcing Accounting Activities has no 
significant effect on the profitability of Small and medium scale enterprises in Nigeria. The respondents views show clearly the fact that most SMEs do not outsource their accounting activities. They do carry out their recording and reporting internally. A fact still stands that, most SMEs do not have an established record keeping habit. This has being identified over the years as one of the major weaknesses of SMEs business operations (Onugu, 2005). The result here too may not be unconnected with the fact that SMEs do not appreciate the importance of record keeping. However, from the questionnaire responses, few SMEs who outsourced their accounting services said they benefit from the exercise. The independence nature of the exogenous accountants who are experts and specialists in computing and auditing of accounts for firms may be a reason for the efficacy of their services.

\section{Findings about hypothesis four which is in line with objective four:}

This hypothesis states that, Outsourcing Support Services has no significant effect on the performance of Small and medium scale enterprises in Nigeria. The regression results ( $p=0.019$ and 0.036 for primary and secondary data respectively) show a significant effect of the outsourcing of Support activities such as Shipping/ transportation, IT services/system, training, others on SME's profitability. In line with this, the null hypothesis is rejected and alternative hypothesis accepted.

Here also, just like in the case of back office activities, this finding supports the view by, Lau and Hurly (1997), Kotabe, et al. (1998), Frayer et al. (2000), Gupta and Zheuder (1994), Greer et al. (1999), others that outsourcing of none core activities is correlated to profitability through cost savings, focus on core businesses, cost restructuring, tax benefits and increase turnover. However, due to the discrepancy in our measurement of financial performance with that of Isaksson and Lantz (2015) who measured in terms of ROI and ROE, and Jiang et al. (2006) who measured in terms on ROA, our finding clearly opposes theirs.

In addition, this finding further supports resource-based thinking which as postulated by CK Prahalad and Gary Hamel stipulates that, firms benefit more when resources are channeled towards core activities while the non core activities which here are merely supportive in nature are contracted to an outside vendor (Prahalad and Hamel, 1990). Also worthy of note here is the relevance of this finding to the transaction cost theory which insists that, operations that can be done by an outside vendor at a lower cost should be outsourced. In line with this therefore, support activities such as training are outsourced instead of employing trainers; same as in the case of outsourcing legal services instead of placing a lawyer on their monthly payroll. Additional information about data and results is captured in Additional file 1.

\section{Conclusion and recommendations}

\section{Conclusion}

Base on the above findings, this research concludes that just like large scale organizations, small and medium scale enterprises outsource. They have over the years embarked on outsourcing strategies such as back office activities (such as security services, cleaning services, order processing, others); primary activities (manufacturing, purchases, warehousing, sales force, customer service, others); accounting activities (such as financial reporting, tax processing, others) and support activities (legal services shipping/ transportation, IT services/ 
system, training, others). These outsourcing activities have over the years led to their increase in profitability.

Also, base on the findings of this research, this research concludes that, Most SMEs outsource more of their primary activities than others which are backup, or supporting in nature. This act is unlike the large organizations which outsource more of their non core activities. However, not every SME outsource. Also, some which outsource have not being managing it effectively. Worthy of note here is the fact that, some which outsource do so without much consideration of their area of operation thereby not utilizing fully the merits of this strategy.

\section{Recommendations}

The researcher therefore recommends that;-

i. SMEs should embark more on outsourcing strategies to attain the benefits of cost savings/restructuring which results in better customer service at profit.

ii. Outsourcing process management should be taken seriously to better reap the benefits of this maintenance/growth strategy. Follow up steps through effective communication and monitoring should be employed.

iii. Also, SMEs should ensure that, the costs of managing the outsourcing process is not greater than the benefits generated by the outsourcing program.

iv. Record keeping is a very vital aspect of business operations. However, base on the responses captured above, it is clear that SMEs attach less value on its record keeping. This research therefore submits that, owing to the unqualified imperativeness of accounting function in today's business word, SMEs should take this function with all seriousness and thus outsource it to competent vendors who can carry out this function better or at a cheaper rate than putting accountants on their payrolls.

\section{Contribution to knowledge}

Issakson and Lantz (2015) carried out a research on outsourcing strategies and their impact on SMEs performance in Sweden and realized through regression results that, all the four strategies have no effect on financial performance of SMEs as measured in terms of Returns on Equity (ROE) and Return on Assets (ROA).

This research has taken a step to replicate their research here in Nigeria; focusing on profitability as a measure of performance and realized that, three of the strategies (Back office, Primary activities and Support activities) have significant effect on the profitability of SMEs except outsourcing of accounting activities whereby, there is a high indication that most don't even outsource here in Nigeria.

This research adds to the literature on outsourcing strategy and Small/medium scale business operations. It fills a gap by providing local evidence as to the effect of various outsourcing strategies on the organizational performance of small and medium scale businesses in Beenue State, Nigeria. Also, it will be quite useful for proceeding researchers who may use it as a background for further research.

\section{Limitations of the study}

Aside the common but less strong limitations to a research such as time constraint, lack of resource materials, financial constraint, others, this research is constrained by; 
Lack of records: Ordinarily one would have preferred to present and analyze financial records of all these organizations to arrive at the implication of their outsourcing practices but due to the presence of insufficiently and so skeletal records, this research has depended more on the responses of the SMEs owners/Managers to arrive at the financial implication of their outsourcing practices. This is a threat to this research as a common error or misinformation by the respondents can mar the truism of its findings.

Limited scope: This study is limited by its small sample across a wide range of business sectors and organizations. Here, only 233 SMEs are sampled among the almost uncountable SMEs in Nigeria. The scope here is also Makurdi metropolis which is a feint representation of Nigeria.

\section{Suggestions for further studies}

The research by Issakson and Lantz (2015) and this research, notwithstanding, there is need for a research to ascertain effects of these outsourcing strategies on other non financial performance measures such as SMEs customer satisfaction; employee job satisfaction; employee commitment, others.

\section{Additional file}

Additional file 1: Appendix I. (DOCX $128 \mathrm{~kb}$ )

\section{Acknowledgements}

We sincerely appreciate the help and guidance of our colleagues, friends and relatives; some of which are Dr. Joseph T. Sev, Dr. Saasongo Nongo, Dr. Darius Ikyanyon, Professor F.A Ayatse, Dr. (Mrs) Kwahar, Dr. (Mrs) Omogbai, Dr. Onyeaghala Obioma, Mr. Emmanuel Ejike, Mr. Abel Haruna, Mr. S. H. Dibal, Mr. Anza Abraham T, Mrs. Dinah Anza, Mrs. Faeren Unde- Anza and several others for their various supports to us towards the realization of this research work.

\section{Author details}

* John Agburu is a professor of management at Benue State University, Makurdi, Nigeria.

*Anza Calvin Nyianshima and *Iyortsuun Akuraun Shadrach are lecturers in the department of Business Administration, Federal University, Wukari, Nigeria.

Funding

This study is partly funded by Federal University, Wukari.

Availability of data and materials

Data and supporting materials for this research are attached as Additional file 1. More information shall be provided when required.

\section{Authors' contributions}

Mr. NCA reviewed the literature and administered the questionnaires, Mr. ASI analyzed the data collected and presented for easy understanding while Professor JIA did the compilation in addition to technical support in mentoring the aforementioned authors. Also, all authors read and approved the final manuscript.

Competing interests

The authors declare that they have no competing interests.

\section{Publisher's Note}

Springer Nature remains neutral with regard to jurisdictional claims in published maps and institutional affiliations.

\section{Author details}

${ }^{1}$ Department of Business Administration, Benue State University, Benue State, Makurdi, Nigeria. ${ }^{2}$ Department of

Business Administration, Federal University, Taraba State, Wukari, Nigeria.

Received: 12 May 2017 Accepted: 26 October 2017

Published online: 21 November 2017

References

Agburu, Jl (2007). Modern research methodology, (2nd ed., ). Makurdi: Kujoma Publishers Ltd. 
Akewushola and Elegbede (2013).Outsourcing Strategy and OrganizationalPerformance: Empirical Evidence from Nigeria Manufacturing Sector. European Scientific Journal. Retrieved on $10^{\text {th }}$ June, 2015 by 7:30 PM from eujournal.org/index. php/esj/article/download/1259/1268.

Akinbola, OA, Ogunnaike, OO, Ojo, OA. (2013). Enterprise outsourcing strategies and marketing performance of fast food industry in Lagos state, Nigeria. Global Journal of Business, Management and Accounting, 3(1), 24-35.

Bolat, T, \& Yilmaz, Ö. (2009). The relationship between outsourcing and organizational performance: is it myth or reality for the hotel sector? International Journal of Contemporary Hospitality Management, 21(1), 7-23.

Busi, M, \& Mclvor, R. (2008). Setting the outsourcing research agenda: The top-10 most urgent outsourcing areas. Strategic Outsourcing: An international J, 1(3), 185-197.

Bustinza, O, Arias-Aranda, D, Gutierrez-Gutierrez, L. (2010). Outsourcing, competitive capabilities and performance: an empirical study in service firms. International Journal of Production Economics, 126(2), 276-288.

Carney, W. (1997). Outsourcing HR and benefits: Navigating the right course. Compensation International, 26(7), 15-23.

Dominguez, L (2006). The managers' step-by-step guide to outsourcing. Boston: McGraw Hill Companies.

Foster, TA. (1999). Lessons learned. Logistics Management and Distribution Journal, 38(4), 67-69.

Frayer, JK, Scannell, JD, Thomas, V. (2000). An empirical investigation of global sourcing strategy effectiveness. Journal of Supply Chain Management, 36(2), 29-38.

Gilley, KM, Greer, CR, Rasheed, AA. (2004). Human resource outsourcing and organizational performance in manufacturing firms. Journal of Business Research, 57(3), 232-240.

Gilley, KM, \& Rasheed, A. (2000). Making more by doing less: An analysis of outsourcing and its effects on firm performance. Journal of Management, 26(4), 763-790.

Goldstein, A. (1999). Outsourcing Survey. www.outsourcingbpo.com/html/goldstein.html.

Greer, CR, Youngblood, SA, Gary, DA. (1999). Human resource management outsourcing: The make or buy decision. Academy of Management Executive, 13(3), 85-96.

Gro"ßler, A, Laugen, BT, Laugen, R, Fleury, A. (2012). Differences in outsourcing strategies between firms in emerging and in developed markets. Differences in outsourcing strategies between firms in emerging and in developed markets. International Journal of Operations \& Production Management, 33(3), 296-321.

Gupta, M, \& Zheuder, D. (1994). Outsourcing and its impact on operations strategy. Production and Inventory Management Journal, 35(3), 70-76.

Guterl, F. (1996). How to manage your outsourcer. Datamation, 79-83.

Gyemang, DAikins, I, Asibey, O, Broni, A. (2014). Evaluating the impact of outsourcing of non-Core functions in THE Hotel industry: A case study of Anita, Noda and golden gate hotels. European Journal of Business and Innovation Research, 2(3), 25-45.

Harward, D. (2010). 4 Sourcing Strategies - Which is best for your business? https://www.trainingindustry.com/blog/ outsourcing/4-sourcing-strategies-which-is-best-for-your-business. Accessed on 21 Aug 2017.

Hayes, D.C., J.E. Hunton and J.L. Reck (2000) "Information systems outsourcing announcements"

Hayward, C. (2002). Outsourcing the finance function. www.cimaglobal.com/financialmanagement. Retrieved on 20th august, 2017 by $5: 00 \mathrm{pm}$

Hill, W.L. (1997). International business competing in the global market place. Boston: Mc Graw Hill Companies. International Journal of Purchasing and Materials, 46-51.International Journal of Operations \& Production Management, Vol. 26(12) p. 1280-1300.

Irefin I.A, Olateju O.I \& Hammed G.O,(2012). Effect of Outsourcing Strategy on Project Success. Transnational Journal of Science and Technology July 2012 edition vol. 2, No.6

Isaksson, A, \& Lantz, B. (2015). Outsourcing strategies and their impact on financial performance in small manufacturing firms in Sweden. International Journal of Business and Finance Research.

Jae, NE, Minh, QH, Kwok, RC, Shih, MP (2000). The Evolution of outsourcing Research: What is the Next Issue. Proceedings

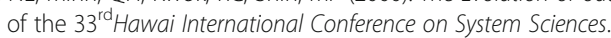

Jennings, D. (1997). "Strategic guidelines for outsourcing decisions". Journal of strategic changes. Vol. 32. Pp.85-96, April 6. Make or buy decision. Academy of Management Executive, 13(3), 85-96 Management Executive 6(1) 7-22. Organization 11, p. 19-33.

Jiang, B., G.V. Frazier and E.L. Prater (2006) Outsourcing effects on firms' operational performance

Jones, W. (1997). Outsourcing basics. Information Systems Management, 14(1), 66-69 Journal of information Systems, Vol. 14(2) p. 109-125.

Kotabe, M, Murray, J, Javalagi, R. (1998). Global sourcing of service and market performance: An empirical investigation. Journal of International Marketing, 6(4), 10-13.

Krell, E (2007). Outsourcing the finance and accounting functions. CIMA, AICPA and CMA Canada: Management Accounting Guideline.

Kroes, JR, \& Ghosh, S. (2010). Outsourcing congruence with competitive priorities: Impact on supply chain and firm performance. Journal of Operations Management, 28(2), 124-143.

Kumaran S. (2013). Top 10 benefits of outsourcing accounting and payroll services. https:/www.invensis.net/blog/finance-andaccounting/top-10-benefits-of-outsourcing-accounting-and-payroll-services. Retrieved on 21st August, 2017 by 6:00pm.

Lau, RS, \& Hurly, CN. (1997). Outsourcing through strategic alliances. Management Journal, 38(2), 52-57.

Leavy, B. (2004). Outsourcing strategies: Opportunities and risks. Strategy and Leadership, 32(6), 20-25.

Lever, S. (1997). An analysis of managerial motivations behind outsourcing practices in human resources. Human Resource Planning, 20(2), 37-47.

Malhorta, Y. (1997). An empirical analysis of the determinants of information systems productivity and the role of outsourcing policy. Virtual Institute of Information, 38-46 www.brint.com/papers/outsource.

Nazeri A. Gholami R \& Rashidi, S. (2012). Outsourcing and its impact on operational PerformanceProceedings of the 2012 International Conference on Industrial Engineering and Operations Management Istanbul, Turkey, July 3 - 6, 2012

Nzelibe, CGO, \& llogu, GU (1999). Fundamentals of research methods. Enugu: Optimal International Ltd. 211 Pp.

Onugu, BA (2005). Small and medium scale enterprises (SMEs) in Nigeria: Problems and prospects. A P.hD Desertation Submitted to the Department of Management: St. Clements University.

Orsaah, S (2009). Introduction to Behavioural research. Makurdi: Aboki Publishers.

Prahalad, C.K., Hamel, G (1990): The core competence of the corporation, Harvard Business Review, Vol. 68, No. 3, p79-91. 
Quinn, BJ. (2000). Outsourcing innovation: The new engine of growth. Sloan Management Review, 41(14), 13-23. Quinn, JB (1992). Intelligent Enterprise: A knowledge and service based paradigm for industry. New York: Free Press. Ramarapu, N, Parzinger, M, Lado, A. (1997). Issues in foreign outsourcing. Information Systems Management, 7-31. Sev, JT (2009). An Emphirical Assesment of Outsourcing: A strategy for Organisational effectiveness in Nigerian corporate sector (a survey of some corporate Organisations in Nigeria). An Unpublished Research Survey.

Sharpe, M. (1997). Outsourcing gains speed in corporate world. Journal of Labor Research, 535-549.

Steensma, KR, \& Corley, KG. (2000). On the performance of technology-sourcing partnerships: The interaction between partner interdependence and technology attributes. Academy of Management Journal, 43(6), 1045-1067 Technology Management, 17(1-2), 109-28.

Suraju, R.F. \& Hamed, A.B. (2013). Outsourcing services as a strategic tool for organizational performance: An exploratory study of Nigerian food, beverage, and tobacco industry. Journal of Management Policies and Practices 1(1); June 2013 pp. 01-20.

TaskUs (2014). Outsourcing Back Office Operations. https://www.taskus.com/blog/outsourcing-back-office-operations. Retrieved on 21st August, 2017 at 4:00pm

Yalokwu, PO (2006). Fundamentals of management. Edition, Lagos: Africa Centre for Management.

Yeboah, A. (2013). The relationship between outsourcing and organizational performance. European Journal of Business and Management, 5(2), 2013.

Zikmund, WG (2010). Business research methods. Florida: The Dryden Press.

Submit your manuscript to a SpringerOpen ${ }^{\circ}$ journal and benefit from:

- Convenient online submission

- Rigorous peer review

Open access: articles freely available online

- High visibility within the field

- Retaining the copyright to your article

Submit your next manuscript at $\gg$ springeropen.com 